\title{
LA JUSTICIA PENAL EN LOS ESCENARIOS POSCONFLICTO
}

\author{
Alicia Gil ${ }^{1}$, Elena Maculan ${ }^{2}$ \\ Instituto Universitario "General Gutiérrez Mellado"/UNED
}

\begin{abstract}
Resumen:
Históricamente, en las situaciones de posconflicto se han ofrecido soluciones diferentes para enfrentarse al legado de los crímenes del pasado, en función de la coyuntura política y social del momento. Sin embargo, la construcción teórica que parece predominante en la época actual tiende a otorgar a la justicia penal un protagonismo absoluto en estos contextos. Este artículo propone un análisis, que suele obviarse, de los fines y las posibilidades concretas de este instrumento en relación con las víctimas y con la sociedad. Nuestra tesis es que, debido a la excepcionalidad de estas situaciones, son necesarios un ejercicio de ponderación entre todos los intereses y objetivos en juego y la flexibilización de la aplicación de la justicia penal, en búsqueda de la mejor combinación posible para garantizar el objetivo último de mantenimiento del orden social y de una convivencia pacífica entre los individuos que componen una sociedad.
\end{abstract}

Palabras Clave: Justicia penal, justicia transicional y posconflicto, retribución, prevención, justicia restaurativa

Title in English: Criminal justice in post-conflict scenarios

\begin{abstract}
:
In post-conflict situations, different solutions have been offered to confront the legacy of past crimes, depending on the political and social situations of the moment. However, the theoretical construction that seems prevalent today tends to give criminal justice absolute prominence in these contexts. This article proposes an analysis, which is often overlooked, of the specific purposes and possibilities of this instrument in relation to victims and society. Our thesis is that, due to the exceptionality of these situations, an exercise in weighting between all the interests and objectives at stake and the flexibility of the application of criminal justice are necessary, in search of the best possible combination for ensure the ultimate objective of maintaining the social order and peaceful coexistence between the individuals who make up a society.
\end{abstract}

Key Words: Criminal justice, transitional justice and post-conflict, retribution, prevention, restorative justice

Copyright @ UNISCI, 2019.

Las opiniones expresadas en estos artículos son propias de sus autores, y no reflejan necesariamente la opinión de UNISCI. The views expressed in these articles are those of the authors, and do not necessarily reflect the views of UNISCI.

\footnotetext{
${ }^{1}$ Alicia Gil es Catedrática de Derecho penal y Directora del Departamento de Derecho penal y Criminología, UNED, Pofesora del Instituto Universitario "General Gutiérrez Mellado"

E-mail: <agil@der.uned.es >

${ }^{2}$ Elena Maculan es Investigadora posdoctoral con contrato Ramón y Cajal, UNED

E-mail: <emaculan@igm.uned.es>.

DOI: http://dx.doi.org/10.31439/UNISCI-64
} 


\section{Introducción ${ }^{3}$}

En el presente artículo vamos a analizar el papel de la justicia penal en el marco de la justicia transicional y postconflicto ${ }^{4}$. Entendemos por justicia transicional y posconflicto el conjunto de medidas legales y políticas que una sociedad puede aplicar para superar una experiencia de conflicto y violencia colectiva.

Históricamente, en las situaciones de posconflicto se han ofrecido soluciones diferentes para enfrentarse al legado de los crímenes del pasado, en función de la coyuntura política y social del momento ${ }^{5}$. Así, se han aplicado modelos retributivos puros, centrados en el ejercicio de la acción penal y del correspondiente castigo, sin descuento ni limitación alguna (quizás la experiencia más relevante en este sentido fue la respuesta a los crímenes del nazismo por parte de los Aliados después del segundo conflicto mundial) y, en el extremo opuesto, modelos del olvido, con distintas variantes, desde sistemas en los que se combinaron medidas de reconocimiento y reparación a las víctimas con amnistías incondicionadas aprobadas por un parlamento democrático, como son los casos español ${ }^{6}$ o uruguayo $^{7}$, hasta aquellos otros en los que la impunidad de los criminales fue garantizada por ellos mismos ${ }^{8}$. Sin embargo, con el tiempo, y ante los problemas prácticos y de legitimidad que planteaban estas soluciones "radicales", ha ido apareciendo una batería de modelos mixtos o combinados ${ }^{9}$, en los que la justicia penal aparece como uno de los mecanismos encargados de ofrecer una respuesta satisfactoria al legado de la época de violencia colectiva, pero al mismo tiempo padece modificaciones, limitaciones y suspensiones en distintas formas y grados.

La experiencia que quizás más claramente ha marcado este cambio de rumbo fue la de Sudáfrica, donde se inauguró un tipo de amnistía hasta entonces inédito. Ya no se trataba de una auto-amnistía absoluta, aprobada por los propios criminales o sus simpatizantes, para todos los crímenes y sin pedir nada a cambio, sino de un complejo e interesante mecanismo por el cual los criminales podían beneficiarse de una amnistía condicionada, siempre que declararan públicamente su responsabilidad, contribuyendo de esta manera a la averiguación de lo ocurrido y al reconocimiento público de responsabilidad en sentido amplio ${ }^{10}$.

\footnotetext{
${ }^{3}$ Este artículo es un resultado del proyecto de investigación "El papel de las víctimas en el tratamiento jurídico de la violencia colectiva" financiado por el Ministerio de Economía y Competitividad. Para mayor información pueden consultarse, entre otras publicaciones derivadas del proyecto, Gil Gil, Alicia y Maculan, Elena (dirs.) (2017): La influencia de las víctimas en el tratamiento jurídico de la violencia colectiva, Madrid, Dykinson

${ }^{4}$ No profundizaremos, por tanto, en otros fines de la justicia transicional (verdad, reparación, garantías de no repetición), ni nos pronunciaremos sobre el tema de la responsabilidad civil.

${ }^{5}$ Para un análisis en clave histórica de las experiencias transicionales del pasado, desde la Grecia Antigua, véase Elster, Jon (2004): Closing the books. Transitional Justice in Historical Perspective, Cambridge, CUP.

${ }^{6}$ Gil Gil, Alicia (2009): La justicia de transición en España: de la amnistía a la memoria histórica, Barcelona, Atelier.

${ }^{7}$ Sobre las vicisitudes en el tiempo del modelo uruguayo véase Galáin Palermo, Pablo (2009): "Uruguay”, en Ambos, Kai; Malarino, Ezequiel y Elsner, Gisela, Justicia de transición, Montevideo, KAS, pp. 391 y ss.

${ }^{8}$ Para una clasificación de los modelos transicionales con un análisis comparado de varias experiencias relevantes al respecto, véase Fornasari, Gabriele (2014): "Giustizia di transizione (diritto penale)", en Enciclopedia del diritto, vol. VIII, Milano, UTET, pp. 547-570; Eser, Albin et al. (2001): Strafrecht in Reaktion auf Systemunrecht : Vergleichende Einblicke in Transitionsprozesse; ein Projektbericht, vol. 6, Freiburg i. Br., Iuscrim.

${ }^{9}$ Fornasari, op. cit., pp. 552 y ss.

${ }^{10}$ Lollini, Andrea (2011): Constitutionalism and transitional justice in South Africa, Oxford-New York, Berghan Books; Du Bois-Pedain, Antje (2007): Transitional Amnesty in South Africa, Cambridge, CUP; Sarkin-Hughes, Jeremy (2004): Carrots and Sticks: The TRC and the South African Amnesty Process, Cambridge, Intersentia.
} 
A partir de ese modelo, que muchos expertos coinciden en considerar exitoso ${ }^{11}$, numerosas sociedades que han vividos etapas transicionales y posconflicto han experimentado soluciones que combinaban de manera diferente una intervención penal retributiva en sentido clásico, pero de alguna manera limitada, con otras medidas, como comisiones de la verdad ${ }^{12}$, mecanismos de justicia restaurativa ${ }^{13}$, esquemas de reparación para las víctimas, institutos de justicia tradicional $^{14}$.

Un caso especialmente interesante en este sentido es el proceso de paz colombiano, que ha aplicado y está aplicando un conjunto de mecanismos y soluciones diferentes, desarrollados en el marco de la justicia de transición, en el intento de poner fin a un conflicto armado interno larguísimo y todavía activo. En Colombia se han aplicado, de manera separada y en momentos históricos diferentes, la persecución penal ordinaria, medidas de indulto y de suspensión de la pena, comisiones de la verdad, mecanismos de reparación, la reducción de penas a cambio de la contribución de los criminales a la satisfacción de las pretensiones de verdad y reparación ${ }^{15}$. En este cuadro complejo se ha insertado el Acuerdo de paz firmado entre el Gobierno y las FARC en 2016, que ha diseñado un proyecto transicional complejo y ambicioso en el que se incorporan soluciones experimentadas en otros países y se combinan penas reducidas, penas alternativas, elementos de justicia restaurativa, amnistías condicionadas e indultos, una comisión de la verdad y criterios de selección y priorización de casos ${ }^{16}$. Todos estos mecanismos se fundamentan en la idea de que, en los contextos transicionales y posconflicto, la justicia penal es uno de los muchos elementos aplicables, pero no el principal, y que puede admitirse su flexibilización en aras de la mejor consecución de los objetivos propios de la transición ${ }^{17}$.

Pese a esta evolución, la construcción teórica que parece predominante en la época actual tiende a otorgar a la justicia penal un protagonismo absoluto en los escenarios de transición y posconflicto, cuestionando aquellas propuestas que de alguna manera limitan o suspenden esta intervención punitiva. El éxito de esta visión se debe, por un lado, al desarrollo de la Justicia penal internacional en las últimas décadas (con la construcción de la Corte Penal

\footnotetext{
${ }^{11}$ Pese a algunos límites en su aplicación concreta: Varney, Howard (2007): "Retribution and Reconciliation: War Crimes Tribunals and Truth Commissions - can they work together?", en Our Freedoms: A Decade's Reflection on the Advancement of Human Rights, Human Rights Institute of the International Bar Association.

${ }^{12}$ Rodríguez Rodríguez, Jorge (2017): Derecho a la verdad y Derecho Internacional en relación con graves violaciones de los Derechos Humanos, Madrid, Instituto Berg; Freeman, Mark (2006): Truth Commissions and Procedural Fairness, Cambridge, CUP; Hayner, Priscilla: "Fifteen Truth Commissions - 1974 to 1994: A Comparative Study", Human Rights Quarterly, no 16 (1994), pp. 597-665.

${ }^{13}$ Como en Timor Este, donde la Community Reconciliation Procedure preveía que los sujetos implicados en la comisión de delitos (menores) tenían que declarar su responsabilidad en una audiencia pública en la comunidad a la que pertenecían, ante un jurado formado por las autoridades locales y, en caso de ser declarados culpables, eran condenados a una medida de reparación como una disculpa pública, la restitución de los bienes sustraídos o destruidos, la realización de trabajos de utilidad pública, cumplida la cual estaban libres de toda responsabilidad civil y pena: Burgess, Patrick (2005): “Justice and reconciliation in East Timor", Criminal Law Forum, no 15, pp. 135-158.

${ }^{14}$ Como los tribunales Gacaca en Ruanda: Bornkamm, Paul Christoph (2012): Rwanda's Gacaca courts, Oxford, OUP.

${ }^{15}$ Vacas Fernández, Félix (2015): El Derecho Internacional ante el conflicto en Colombia, Valencia, Tirant lo Blanch; Aponte Cardona, Alejandro (2009): "Colombia”, en Ambos, Kai; Malarino, Ezequiel y Elsner, Gisela (coords.): Justicia de transición, Montevideo, KAS, pp. 235-295.

${ }^{16}$ Maculan, Elena (2017): "El proceso transicional colombiano en perspectiva comparada", en Gil Gil, Alicia; Maculan, Elena y Ferreira, Susana (dirs.): Colombia como nuevo modelo para la justicia de transición, Madrid, IUGM, pp. 53 y ss.

${ }^{17}$ Gil Gil, Alicia (2017): "El tratamiento jurídico de los crímenes cometidos en el conflicto armado colombiano. La problemática jurídica en el marco de la dicotomía paz-justicia”, en Gil Gil; Maculan y Ferreira (dirs.): Colombia como nuevo modelo, op. cit., pp. 22 y ss.
} 
Internacional y la proliferación de los tribunales penales híbridos o mixtos ${ }^{18}$ ) y, por el otro, a la postura maximalista mantenida por algunos tribunales de derechos humanos, especialmente la Corte Interamericana de Derechos Humanos ${ }^{19}$. Estos, a partir de una interpretación evolutiva de sus instrumentos fundadores, han ido afianzando la idea, resumida en los lemas de "lucha contra la impunidad" y "no hay paz sin justicia", de que la justicia penal es el mecanismo principal e irrenunciable de toda experiencia de transición y posconflicto, y de que constituye al mismo tiempo un derecho de las víctimas, entendido como un verdadero derecho al castigo de los delincuentes ${ }^{20}$. Estas construcciones se enmarcan, además, en una tendencia prácticamente global a otorgar a las víctimas de delitos una nueva centralidad en la política criminal e incluso en la intervención punitiva, de la que habían estado tradicionalmente excluidas $^{21}$.

El propósito de este artículo es analizar si este pretendido protagonismo de la justicia penal, entendida como la única forma de reparación posible en casos de graves violaciones de los derechos humanos y como medio de satisfacción de las víctimas, tiene una base sólida desde el punto de vista penal y filosófico. Creemos que las transformaciones que estas construcciones implican en el concepto mismo de la justicia penal, de sus fines y de sus límites ${ }^{22}$, deberían arraigarse en una fundamentación teórica satisfactoria que, sin embargo, no encontramos si analizamos el fenómeno desde el prisma de la Filosofía del derecho y del Derecho penal, con el enfoque teórico y crítico que caracterizaba el pensamiento de nuestra querida compañera Paloma García Picazo.

\footnotetext{
${ }^{18}$ Maculan, Elena (2019): "La Corte Penal Internacional” y Liñán Lafuente, Alfredo (2019): “Los Tribunales penales híbridos e internacionalizados", ambos en Gil Gil, Alicia y Maculan, Elena (dirs.): Derecho penal internacional, Madrid, Dykinson, pp. 83 y ss. y 115 y ss., respectivamente.

${ }^{19}$ Apoyan esta postura, en la doctrina: Engle, Karen; Miller, Zinaida y Davis, Dennis (2016): Anti-impunity and the Human Rights Agenda, Cambridge, CUP; Bassiouni, M Cherif (2010): "Victims' Rights”, en Idem (ed.), The Pursuit of International Criminal Justice: A World Study on Conflicts, Victimization, and Post-conflict Justice, vol. I, Cambridge, Intersentia, pp. 599 y ss.; Ambos, Kai; Malarino, Ezequiel y Elsner, Gisela (coords.) (2010 y 2011): Sistema interamericano de protección de los derechos humanos y derecho penal internacional, vol. I y vol. II, Montevideo, KAS; Chinchón Álvarez, Javier (2007): Derecho internacional y transiciones a la democracia y la paz: Hacia un modelo para el castigo de los crímenes pasados a través de la experiencia iberoamericana, Sevilla, Parthenos, pp. 235 y ss. y 434 y ss.

${ }^{20}$ Malarino, Ezequiel (2010): “Activismo judicial, punitivismo y nacionalización. Tendencias antidemocráticas y antiliberales de la Corte Interamericana de Derechos Humanos", en Ambos et al. (coords.), Sistema interamericano, op. cit., tomo I, pp. 25-61. El Tribunal Europeo de Derechos Humanos, que tradicionalmente ha mantenido una postura más prudente, en algunos pronunciamientos recientes parece acercarse a su homólogo interamericano: Seibert-Fohr, Anja (2009): Prosecuting serious human rights violations, Oxford, OUP, pp. 118 y ss.; Ambos, Kai y Böhm, Laura (2011): “Tribunal Europeo de Derechos Humanos y Corte Interamericana de Derechos Humanos ¿Tribunal tímido y tribunal audaz?”, en Ambos et al. (coords.), Sistema interamericano, op. cit., tomo II, pp. 55 y ss.; Viganó, Francesco: "Sobre las obligaciones de tutela penal de los derechos fundamentales en la jurisprudencia del TEDH”, en Mir Puig, Santiago y Corcoy Bidasolo, Mirentxu (dirs.) (2012): Garantías constitucionales y Derecho penal europeo, Madrid, Marcial Pons, pp. 320 y ss.; Tomás-Valiente Lanuza, Carmen: "Deberes positivos del Estado y Derecho penal en la jurisprudencia del TEDH”, InDret, no 3 (2016), pp. 6 y ss.

${ }^{21}$ Prittwitz, Cornelius: "The Resurrection of the Victim in Penal Theory", Buffalo Criminal Law, n 3 (1999), p. 109 y ss.; Cerruti, Pedro (2009): "Procesos emocionales y respuestas punitivas: acerca del activismo penal de las víctimas del delito", Revista Electrónica de Psicología Política, n. 20, p. 15; Cerezo Domínguez, Ana Isabel (2010): El protagonismo de las víctimas en la elaboración de las leyes penales, Valencia, Tirant lo Blanch, pp. 37 y ss.; Lupária, Luca y Parizot, Raphaële (2015): “Which good practices in the field of victim protection?”, en Luca Luparia (ed.): Victims and criminal justice. European standards and national good practices, Wolters Kluwer, p. 333.

${ }^{22}$ Silva Sánchez, Jesús María : "Una crítica a las doctrinas penales de la "lucha contra la impunidad” y del "derecho de la víctima al castigo del autor", ", Revista de Estudios de la Justicia, no 11 (2009) p. 35; Pastor, Daniel R. (2011): "La ideología penal de ciertos pronunciamientos de los órganos del sistema interamericano de derechos humanos: ¿garantías para el imputado, para la víctima o para el aparato represivo del Estado?”, en Ambos et al. (coords.), Sistema interamericano, op . cit., tomo II, p. 481.
} 
La intervención penal se receta muchas veces, en los contextos transicionales y posconflicto, sin detenerse previamente en considerar los fines y las posibilidades concretas de este instrumento en relación con las víctimas y con la sociedad. Nuestra tesis es que no puede sostenerse un derecho de las víctimas al castigo de los criminales y que, paralelamente, la justicia penal no es una medida suficiente, ni, muchas veces, la más apropiada, para proporcionar una respuesta adecuada al complejo entramado de objetivos que maneja la justicia transicional y posconflicto. Por el contrario, la idea de que una intervención penal retributiva debe ser un ingrediente esencial de la justicia en estos contextos carga la justicia penal de fines que esta no está capacitada para alcanzar, o que, en todo caso, pueden alcanzarse de manera más satisfactoria a través de otros mecanismos. La justicia penal debería considerarse siempre, incluso en contextos transicionales y posconflicto, o quizás precisamente más en estos, como solamente una de las muchas herramientas que los Estados tienen a disposición para la consecución del objetivo último, es decir, el mantenimiento del orden social o, lo que es lo mismo, del conjunto de bienes jurídicos de una sociedad.

\section{Justicia penal, retribución y víctimas}

\subsection{La fundamentación teórica}

Cuando, principalmente desde el ámbito de los derechos humanos, bien sea las resoluciones de los tribunales y órganos dedicados a su protección, bien las ONGs o la doctrina, se reclama que el castigo del delincuente es un derecho de las víctimas y el remedio para la lesión de sus derechos, se hace sin ningún estudio, ni teórico ni empírico, sobre los posibles fines y efectos de la pena y del proceso penal. Sin embargo, en la literatura penal y en la filosofía jurídica sí existe este tipo de estudios y de propuestas. Por ello aquí vamos a repasar las principales discusiones que desde los fines de la pena y del derecho penal nos acercan a esta ideología.

Algunos autores han querido ver en estas doctrinas un regreso a las concepciones absolutas de la pena ${ }^{23}$, para las que el castigo era mera retribución, en el sentido kantiano, del daño causado. Pero en realidad las corrientes que comentamos no coinciden con aquellas teorías absolutas de la pena. Si bien comparten la idea del castigo como un imperativo, como una obligación (de la sociedad, del Estado), y la frecuente apelación a la justicia como fundamento y el reclamo de una pena taliónica ${ }^{24}$, no atemperada por consideraciones político-criminales o por la ausencia de necesidades preventivas, y la exigencia del cumplimiento íntegro de la misma ${ }^{25}$, existen notables diferencias entre $\operatorname{ambas}^{26}$. La teoría clásica de la retribución pone su atención, a la hora de fundamentar la pena, en el delincuente, en su merecimiento de pena, y no en la víctima y su satisfacción ${ }^{27}$. La teoría del derecho penal orientada a la víctima no centra su atención, por el contrario, en el pasado, sino en el presente ${ }^{28}$.

Modernamente también se han ensayado otros intentos de fundamentar que el derecho penal y la pena tienen como fin la satisfacción de la víctima o que son un derecho de esta. Por ejemplo, apelando a la evolución desde la venganza a la pena. Así, se argumenta que la renuncia a la justicia privada para ceder al Estado el monopolio del castigo conlleva un compromiso de

\footnotetext{
${ }^{23}$ González Zapata, Julio: "La justicia transicional o la relegitimación del derecho penal”, Estudios Políticos, n 31 (2007), p. 27; Nino, Carlos S. (1996): Radical Evil on Trial, London, Yale University Press, pp. 111-2.

${ }^{24}$ Kant, Immanuel (1838): Die Metaphysik der Sitten, Modes und Baumann.

${ }^{25}$ Durán Migliardi, Mario (2011): "Teorías absolutas de la pena: origen y fundamentos. Conceptos y críticas fundamentales a la teoría de la retribución moral de Immanuel Kant a propósito del neo-retribucionismo y del neoproporcionalismo en el derecho penal actual", Revista de Filosofía, no 67, p. 127.

${ }^{26}$ Prittwitz, op. cit., p. 118.

${ }^{27}$ Similar Feijoo Sánchez, Bernardo (2014): La legitimidad de la pena estatal, Madrid, Iustel, pp. 24 y ss.

${ }^{28}$ Silva Sánchez, "Una crítica la las doctrinas penales", op. cit., p. 56.
} 
este $^{29}$. Sin embargo, esta construcción supone afirmar una especie de derecho natural, no solo a la autoprotección, sino al castigo, cuya existencia es más que dudosa. Además, hoy en día, después de casi un milenio, la pena estatal ya no se puede ver como un imaginario acto de cesión por parte de la víctima, sino como fruto de la voluntad del legislador democrático ${ }^{30}$. En todo caso, el principal problema de estas argumentaciones reside en que la apelación a la tradición o a la evolución histórica no puede sustituir a la fundamentación que se busca. Es decir, la constatación de la evolución histórica desde la institución de la venganza hasta la pena no explica por qué y para qué se castiga, ni hoy, ni entonces. Solo serviría, por tanto, para una ineludible indagación sobre los fines de la arcaica institución de la venganza, en tanto pudiera ilustrarnos de alguna manera sobre el fundamento de la pena actual. Y este paso, en la mayoría de los casos, no se da.

Más interesantes resultan, en cambio, los modernos intentos surgidos en la doctrina, tanto alemana como anglosajona, de fundamentar la finalidad de la pena en la satisfacción de la víctima, bien argumentando los posibles efectos beneficiosos que puede tener en esta, en el sentido de que se sienta mejor ${ }^{31}$, o bien, en una variante, defendiendo que su finalidad es la eliminación de un daño a la víctima cuyo origen es el delito, pero que es diferente a la concreta lesión del bien jurídico atacado por aquel.

Entre los efectos beneficiosos de la pena suelen citarse el reconocimiento a la víctima de haber sufrido un hecho injusto, con la consiguiente expresión de que lo ocurrido no ha sido un mero accidente o producto de la mala suerte o la consecuencia de los propios errores ${ }^{32}$, y el aseguramiento simbólico de no repetición, con sus efectos de protección del sentimiento de seguridad de la víctima ${ }^{33} \mathrm{o}$ de su autoestima ${ }^{34}$, y la evitación de la culpabilización ${ }^{35}$ junto con la expresión de condolencia y de solidaridad de la sociedad ${ }^{36}$ y consiguiente "resocialización" o reintegración de la víctima ${ }^{37}$.

En la segunda variante se dice que la pena cumple la función de poner fin a la desorientación en la vida social que sufre la víctima a causa de la falta de confianza en el Derecho $^{38}$, o que su finalidad es liberar a la víctima de la dominación del delincuente ${ }^{39}$, restaurando o reafirmando su valor ${ }^{40}$, o cesar una lesión continuada de su honor que se prolonga

\footnotetext{
${ }^{29}$ Haque, Adil (2005): "Group Violence and Group Vengeance: Toward a Retributivist Theory of International Criminal Law", Buffalo Criminal Law Review, n 9, pp. 273 y ss.

${ }^{30}$ Weigend, Thomas (2010): "Die Strafe für das Opfer"? - Zur Renaissance des Genugtuungsgedankens im Strafund Strafverfahrensrech?”, Zeitschrift für rechtswissenschaftliche Forschung, Baden-Baden, Nomos, p. 45.

${ }^{31}$ Sobre los defensores de esta idea en la doctrina anglosajona Kaufman, Armin (2013): Honor and Revenge. A Theory of Punishment, Springer, pp. 50 y ss.

${ }^{32}$ Günther, Klaus (2002): "Die symbolisch-expressive Bedeutung der Strafe", en Festschrift für Klaus Lüderssen, Baden-Baden, Nomos, p. 218; Reemtsma, Jan Philipp (1999): Das Recht des Opfers auf die Bestrafung des Täters -als Problem, München, C.H. Beck, p. 26.

${ }^{33}$ Holz, Wilfried (2007): Justizgewähranspruch des Verbrechensopfers, Berlin, Duncker \& Humblot, pp. 134 y ss.

${ }^{34}$ Günther, op. cit., pp. 208 y ss., aunque reconoce que la interpretación de ciertos delitos como una humillación es cultural y la quizás inevitable auto-atribución de indefensión o impotencia puede no guardar relación con la realidad.

${ }^{35}$ Hörnle, Tatjana: "Die Rolle des Opfers in der Straftheorie und im materiellen Strafrecht”, Juristen Zeitung, $\mathrm{n}^{\circ}$ 19 (2006), p. 955.

${ }^{36}$ Hörnle, op. cit., p. 955.

${ }^{37}$ Reemtsma, Das Recht des Opfers, op. cit., p. 27.

${ }^{38}$ Ibid., p. 26.

${ }^{39}$ Fletcher, George (1999): “The Place of Victims in the Theory of Retribution", Buffalo Criminal Law Review, $\mathrm{n}^{\mathrm{o}} 3$, pp. 51 y ss.

${ }^{40}$ Murph, Jeffrie y Hampton, Jean (1988): Forgiveness and Mercy, Cambridge, CUP, 1988, p. 132; ulteriores citas en Gert, Heather et al:: "Hampton on the Expressive Power of Punishment", Journal of Social Philosophy, vol. $35, \mathrm{n}^{\circ} 1$ (2004), pp. 79 y ss.
} 
en tanto no hay respuesta penal al delito ${ }^{41}$. Se ha pretendido, también, relacionar la teoría de la pena orientada a la víctima con la prevención general positiva, pero sustituyendo la reafirmación de la norma por la de la víctima ${ }^{42}$, o, en otras palabras, buscando una "resocialización de la víctima" 43.

La doctrina, sin embargo, ha puesto en duda la capacidad de la pena para cumplir con todas estas finalidades ${ }^{44}$. En realidad, los efectos del delito (y del proceso penal) son diferentes en cada víctima ${ }^{45}$, dependiendo de gran variedad de circunstancias ${ }^{46}, y$, por otra parte, muchos de los efectos deseables que los partidarios de estas teorías atribuyen al castigo son alcanzables por otros medios que no supongan la imposición de un mal ${ }^{47}$. Además, esta idea se enfrenta a ulteriores dificultades: Si la pena tiene el único fin de dar satisfacción a la víctima, entonces su medida debería ir determinada exclusivamente por esas necesidades, que son diferentes para cada víctima $^{48}$. Desaparecerían, con ello, la igualdad y la seguridad jurídica en el cálculo de la pena $^{49}$.

Por último, este tipo de construcciones, en lugar de corregir juicios morales o atribuciones de significados erróneos, conllevarían el refuerzo de una reclamación falsa: que existe una correlación entre poder y valor u honor del ser humano ${ }^{50}$.

En conclusión, desde la fundamentación teórica de los fines de la pena y del derecho penal no podemos llegar a una explicación convincente de la existencia de un supuesto derecho de la víctima al castigo.

\subsection{La necesaria reinterpretación de los fines de la pena en relación con las víctimas}

En nuestra opinión, no se puede negar el potencial del castigo penal para producir efectos beneficiosos para las víctimas, sobre todo, el mostrar la injusticia padecida por ellas y el ofrecerles garantías de no repetición, respondiendo de esta manera a sus pretensiones de

\footnotetext{
${ }^{41}$ Kaufman, op. cit., pp. 117 y ss.

${ }^{42}$ Fletcher, "The Place of Victims", op. cit., p. 58.

${ }^{43}$ Reemtsma, Das Recht des Opfers, op. cit., p. 27. Sobre todas estas teorías con mayor detalle Gil Gil, Alicia (2016): "Sobre la satisfacción de la víctima como fin de la pena", InDret, no 4.

${ }^{44}$ Weigend, op. cit., pp. 48 y ss.

45 Páez Rovira, Darío (2011): "Afrontamiento y violencia colectiva", en Idem et al. (coords.), Superando la violencia colectiva, construyendo cultura de paz, Fundamentos, p. 293. Sobre la incapacidad de la pena para "sanar" a la víctima en muchos casos, advierte también, con ulterior bibliografía, Hörnle, op. cit., p. 955.

${ }^{46}$ Los efectos del delito, lo que en Victimología se conocen como “impacto de la victimización”, dependerán de la gravedad del hecho, de la personalidad de la víctima y del contexto en que se encuentre. Véase el "Manual de Justicia para las Víctimas: sobre el uso y aplicación de la Declaración de las Naciones Unidas de Principios Básicos de Justicia para las Víctimas de Delitos y de Abuso del Poder", 1999, pp. 9 y ss., accesible en http://www.worldsocietyofvictimology.org/wp-content/uploads/2014/12/Handbook-on-Justice-Sp.pdf. También Echeburúa, Enrique et al. (2004): "Evaluación del daño psicológico las víctimas de delitos violentos", Psicopatología clínica, legal y forense, vol. 4, n 1-3, pp. 227-244; Muñoz García, Juan Jesús y Navas Collado, Encarnación: "El daño psicológico en las víctimas del terrorismo", Revista de Psicopatología Clínica Legal y Forense, $\mathrm{n}^{\mathrm{o}} 7$ (2007), pp. 147 y ss.

${ }^{47}$ Prittwitz, op. cit., pp. 120-121; Arnoso Martínez, Maitane (2011): "Violencia colectiva y creencias básicas sobre el mundo, los otros y el yo: impacto y reconstrucción”, en Páez Rovira et al. (coords.), Superando la violencia colectiva, op. cit., pp. 265 y ss.; Wenzel, Michael y Okimoto, Tyler: "How acts of forgiveness restore a sense of justice: Addressing status/power and value concerns raised by transgressions", European Journal of Social Psychology, $\mathrm{n}^{\circ} 40$ (2010), pp. 401-417.

${ }^{48}$ No lo ve así Hörnle, op. cit., p. 956, para quien la pena señalada en el código penal para cada infracción ya basta para cumplir con la función expresiva de la solidaridad. De ello se deduce que en su construcción la pena no va dirigida a satisfacer realmente las necesidades de la víctima concreta. Pero la función expresiva de la pena no justifica por sí sola la imposición de un daño: Silva Sánchez, "Una crítica a las doctrinas penales", op. cit., p. 56; Kaufman, op. cit., p. 67; Günther, op. cit., p. 219.

${ }^{49}$ Gil Gil, "Sobre la satisfacción de las víctimas", op. cit.

${ }^{50}$ Gert et al., op. cit., p. 84. Con mayor detalle Gil Gil, "Sobre la satisfacción de las víctimas”, op. cit.
} 
justicia, restaurando su confianza en la ley y en la sociedad y evitando su desocialización. Hay que reconocer que, como seres humanos, nuestro sentido de justicia nos lleva a exigir que las malas acciones sean castigadas. Pero no hay que olvidar que estos sentimientos derivan del mecanismo de reciprocidad ${ }^{51}$, que compartimos con otras especies animales ${ }^{52}$. Se trata de un mecanismo que actúa como instrumento preventivo y que sirve, un última instancia, para promover la conservación del grupo y del individuo como ser social ${ }^{53}$. En otras palabras, aun cuando el castigo sirve para satisfacer las exigencias de reciprocidad tan inherentes a nuestro sistema de relaciones sociales, es un objetivo, al fin y al cabo, instrumental. Es por ello que la satisfacción de las víctimas no puede extrapolarse y ponerse como un fin en sí mismo o como un objetivo superior a los fines clásicos de prevención, ni sustituir al fin principal de la justicia penal, que es la protección de los bienes jurídicos y del orden social ${ }^{54}$.

Por tanto, podemos concluir que una estrategia para satisfacer todos los intereses en juego y con ello construir una paz duradera no debe desatender una respuesta a los crímenes del pasado. Pero dicho esto, el Estado, con su monopolio del ejercicio de la violencia, podría moderar los instintos y las pretensiones de reciprocidad de las víctimas y de la sociedad (que de por sí son legítimos y comprensibles), y someterlos a límites racionales. El Estado debería procurar dar satisfacción a esas pretensiones a través de otros mecanismos, diferentes del penal, y al mismo tiempo ponderarlos con otros objetivos importantes, en búsqueda de la mejor solución posible para alcanzar el fin último del mantenimiento del orden social ${ }^{55}$.

\subsection{El derecho a la justicia}

Al referirnos del derecho de las víctimas a la justicia, sobre el cual tanto hincapié se hace en las experiencias transicionales, es imprescindible adoptar un concepto amplio de justicia, que incluya no solamente la imposición de una condena, sino también las enormes posibilidades que ofrece la justicia restaurativa ${ }^{56}$. Este modelo de justicia busca la reparación del daño

\footnotetext{
${ }^{51}$ Caterina, Raffaele (2015): "La reciprocità: alle origini della vendetta e dello scambio", en Lorini, Giuseppe y Masia, Michelina (a cura di), Antropologia della vendetta, Napoli, ESI, p. 213.

${ }^{52}$ Ibid., p. 212; Aureli, Filippo et al. (1992): "Kin-oriented redirection among Japanese macaques: an expression of a revenge system?", Animal Behaviour, no 44, pp. 283 y ss.

${ }^{53}$ Durkheim, Émile (2008) : De la division du travail social, Paris, Les Presses Universitaires de France. En la actualidad, numerosos estudios desde la Antropología, la Psicología y la Filosofía del derecho apoyan la idea de un fundamento preventivo tanto del castigo (aun cuando este se entienda como retribución), como de la venganza, pues ambos se basan en un mecanismo de reciprocidad. Véanse por ejemplo Rodríguez Horcajo, Daniel (2016): Comportamiento humano, y pena estatal: disuasión, cooperación y equidad, Madrid, Marcial Pons, pp. 308 y ss.; Gil Gil, "Sobre la satisfacción de las víctimas", op. cit., p. 31; Loddo, Olimpia G. (2015): "Reciprocità di aspettative e aspettative di reciprocità nella vendetta", en Lorini y Masia (a cura di), Antropologia della vendetta, op. cit., p. 217; Gollwitzer, Mario y Denzler, Markus (2009): "What makes revenge sweet: Seeing the offender suffer or delivering a message?", Journal of Experimental Social Psychology, no 45 (2009). pp. 840, 843; Miller, Dale T.: "Disrespect and the Experience of Injustice", Annual Review of Psychology, no 52 (2001), p. 541; Chagnon, Napoleon (1988): "Life Histories, Blood Revenge, and Warfare in a Tribal Population" Science, n 4843, pp. 985 y ss.

${ }^{54}$ De manera similar, Rodríguez Horcajo, op. cit., pp. 308 y ss., pone de manifiesto que el sentimiento de justicia es el resultado de la estandarización de una reacción evolutiva positiva. En su opinión, lo que queda de la retribución en la fundamentación de la pena sería nada más que la voluntad de un comportamiento (la pena) que persigue un objetivo favorable.

55 Véase Silva Sánchez, Jesús María (2018): Malum passionis. Mitigar el dolor del Derecho penal, Barcelona, Atelier, pp. 195 y ss., que también hace hincapié en la necesidad de que la justicia penal esté subordinada a otros intereses que le son ajenos. Ello explica, en su opinión, la legitimidad de la reducción de la pena cuando el delincuente lleva a cabo determinadas conductas posdelictivas, como la confesión (Ibid., pp. 122 y ss.).

${ }^{56}$ Para un análisis del concetpo de justicia restaurativa y de su aplicación a los contextos transicionales, véanse entre otros: Clamp, Kerry (ed.) (2016): Restorative Justice in Transitional Settings, Routledge; Tamarit Sumalla, Josep: “Comisiones de la verdad y justicia penal en contextos de transición", InDret, $\mathrm{n}^{\circ} 1$ (2010), p. 21; Braithwaite, John (2002): Restorative Justice \& Responsive Regulation, Oxford, OUP, pp. 16 y ss.; Wenzel y Okimoto, op. cit., pp. 413 y ss. En todo caso, el alcance de la justicia restaurativa y su relación con la justicia penal
} 
ocasionado a la víctima, más que el castigo del criminal, y pretende superar algunas carencias en el sistema tradicional de justicia retributiva ${ }^{57}$. Los mecanismos de justicia restaurativa, como por ejemplo la mediación, están diseñados para que la víctima pueda hacer oír su voz en el procedimiento de resolución del conflicto, lo que favorece la "desvictimización" y puede mitigar sus sentimientos de incomprensión o de culpa. En términos generales, además, estos mecanismos contribuyen, mejor que la justicia penal clásica, al reconocimiento de responsabilidad por parte del criminal, así como a su reinserción en la sociedad y a la recuperación de las relaciones interpersonales vulneradas por los delitos ${ }^{58}$. Por último, la justicia restaurativa tiene un efecto transformador no solamente a nivel interpersonal, sino también en las instituciones estatales y en la comunidad en su conjunto ${ }^{59}$.

La psicología social también ha confirmado la necesidad de un concepto amplio de justicia, que no se limite a la idea de retribución, destacando que la pretensión de justicia de las víctimas se satisface, desde su perspectiva, cuando se recibe, por parte del criminal, una disculpa oficial y un reconocimiento de la injusticia cometida, más que por medio de la imposición unilateral de un castigo estatal. Varios estudios muestran que medidas restaurativas, como la petición de perdón, tienen un efecto reparador que satisface el sentimiento de justicia ${ }^{60}$. Al mismo tiempo, se reafirman los bienes jurídicos vulnerados por el delito, pues la petición de perdón indica, por un lado, que el criminal comparte esos valores, y, por el otro, que reconoce la dignidad de las víctimas.

De acuerdo con esta visión, el castigo penal es por tanto insuficiente, y, a veces, innecesario, para ofrecer justicia a las víctimas ${ }^{61}$. Esto no implica que la justicia restaurativa sea una alternativa al sistema tradicional de justicia penal ${ }^{62}$ : puede ser más bien un mecanismo complementario a este, que permite incorporar nuevos elementos cuya función es humanizar el sistema y ayudar a cumplir con sus fines ${ }^{63}$. Pero cuando se aplica la justicia restaurativa, puede resultar que haya menos necesidad de imponer una pena, si existen otros mecanismos que permiten cumplir, al menos parcialmente, con los fines propios de la justicia penal. Cabe plantearse así la posibilidad de una reducción de la pena, de su sustitución por sanciones alternativas, de una suspensión condicional de la misma ${ }^{64}$. Estas medidas van en contra de la

siguen siendo objeto de debate: véase al respecto von Hirsch, Andrew; Roberts, Julian V. y Bottoms, Anthony E. (eds.) (2003): Restorative Justice and Criminal Justice: Competing or Reconcilable Paradigms, London, Hart Publishing.

${ }^{57}$ Sanz Díez de Ulzurrun, Marina: "Justicia restaurativa y mediación penal”, en Gil Gil, Alicia y Maculan, Elena (dirs.) (2017): La influencia de las víctimas en el tratamiento jurídico de la violencia colectiva, Madrid, Dykinson, respectivamente pp. 121 y ss. y 145 y ss.; Zehr, Howard (2014): The Little Book of Restorative Justice: Revised and Updated, Good Books, pp. 4 y ss.; Johnstone, Gerry y Van Ness, Daniel (eds.) (2007): Handbook of Restorative Justice, London, Willan, pp. 5 y ss.; Liebmann, Marian (2007): Restorative Justice: How It Works, Jessica Kingsley, p. 32. En realidad, la incorporación de una perspectiva restaurativa en el paradigma retributivo clásico también plantea retos conceptuales, como apunta Zedner, Lucia: "Reparation and Retribution: Are They Reconciliable" Modern Law Review, no 57 (1994), pp. 238 y ss.

${ }^{58}$ Johnstone and Van Ness, op. cit.; Liebman, op. cit., p. 32.

59 Así por ejemplo Harris, M. Kay (2004): "An Expansive, Transformative View of Restorative Justice", Contemporary Justice Review, no 7, pp. 117-141; Zehr, op. cit., section 4; Sullivan, Dennis y Tifft, Larry: “The Transformative and Economic Dimensions of Restorative Justice”, Humanity \& Society, nº 22 (1998), pp. 38 y ss. ${ }^{60}$ Wenzel y Okimoto, op. cit., pp. 402-403 y 414.

${ }^{61}$ Ibid.

${ }^{62}$ En contra de lo que defienden algunos abolicionistas, como Bianchi, Herman (1994): Justice as Sanctuary: Toward a System of Crime Control, Bloomington, Indiana University Press, pp. 10 y ss., aunque se trate de una corriente minoritaria hoy en día.

${ }^{63}$ Zehr, op. cit., sección 4, alegando que la "justicia real" puede verse como un "continuum" desde la justicia penal y la justicia restaurativa.

${ }^{64}$ Robinson, Paul H. (2003): "The virtues of Restorative Processes, the Vices of "Restorative Justice", Utah Law Review, no 1 (2003), p. 387. Otros autores, como Silva Sánchez, Malum passionis, op. cit., pp. 219 y ss., consideran 
idea de necesaria proporcionalidad entre el quantum de pena, por un lado, y la gravedad del delito y el grado de culpabilidad, por el otro, que de por sí impediría la reducción de la primera.

Sin embargo, es preciso tener en cuenta que la justicia restaurativa no se puede imponer: su premisa ineludible es que la participación en los mecanismos que ella propone es voluntaria. Ahí reside también la diferencia entre justicia restaurativa y justicia transicional, que es el producto de una política pública y, por tanto, planificada y decidida desde arriba. En conclusión: cuando intentamos combinar justicia restaurativa y justicia transicional nos referimos a que los procesos transicionales pueden (y deberían) prever, por un lado, espacios para la aplicación de mecanismos de justicia restaurativa y, por el otro, deberían adoptar una aproximación o perspectiva restaurativa en su diseño, adaptándola al específico contexto de la transición ${ }^{65}$. Por ejemplo, algunos mecanismos transicionales, como las comisiones de la verdad, pueden clasificarse como formas de justicia transicional que adoptan una perspectiva restaurativa, en la medida en que ofrecen un reconocimiento formal del injusto cometido y, más aun, cuando prevén la petición o el ofrecimiento de perdón ${ }^{66}$. Y lo mismo puede decirse de las excusas oficiales de las instituciones estatales, de las ceremonias oficiales de reconocimiento de las víctimas o de los programas de indemnización y reparación desarrollados por el Estado.

Por supuesto, ni siquiera la justicia restaurativa, o la justicia transicional con un enfoque restaurativo, es suficiente para alcanzar todos los objetivos de un proceso transicional, pues se centra en el nivel interpersonal. Aunque algunos de sus mecanismos producen potenciales beneficios para la comunidad, no pueden responder a los aspectos "macro" del conflicto, como los políticos, sociales y económicos, que están relacionados con la construcción de paz. Para ello, se requiere el uso de otros instrumentos, que van incluso más allá del concepto de justicia (tanto penal como restaurativa), en aplicación del que se ha llamado enfoque integral u holístico de los procesos transicionales ${ }^{67}$.

Esta visión amplia se ha definido también como "justicia transformadora", un concepto que engloba un conjunto de medidas y políticas que producen un impacto en la situación política, social y económica de muchos actores del proceso de paz, más allá de los objetivos tradicionales de verdad y justicia entendida como responsabilidad ${ }^{68}$.

\section{Justicia penal, prevención y sociedad}

Pasando ahora a analizar la cuestión desde el prisma de la sociedad, se puede afirmar que los fines que la justicia penal está llamada a cumplir para ella sufren cambios importantes en los contextos transicionales y posconflicto. Por un lado, la propia naturaleza de los crímenes a los que se pretende dar respuesta (son crímenes masivos y, en la mayoría de los casos, sistemáticos) ponen en entredicho los fines tradicionalmente atribuidos a la pena, es decir, la prevención general, la prevención especial y la retribución. Por otro lado, en este ámbito hay una tendencia evidente a encomendar a la justicia penal un conjunto de fines adicionales, más propios de los

\footnotetext{
en cambio que los procesos restaurativos deben aplicarse siempre después de la haber culminado el proceso penal y por separado de este, para garantizar la sinceridad del delincuente.

${ }^{65}$ Para más detalle, véanse Clamp, op. cit.; Varona, op. cit., pp. 167 y ss.

${ }^{66}$ Gibson, James L.: "Truth, Justice, and Reconciliation: Judging the Fairness of Amnesty in South Africa", American Journal of Political Science, $\mathrm{n}^{\circ} 4$ (2002), p. 547.

${ }^{67}$ Stahn, Carsten: “The Geometry of Transitional Justice: Choices of Institutional Design”, Leiden Journal of International Law, $\mathrm{n}^{\circ} 18$ (2005), pp. 425 y ss.

${ }^{68}$ Gready, Paul y Robin, Simon: "From Transitional to Transformative Justice: A New Agenda for Practice" Internationakl Journal of Transitional Justice, $\mathrm{n}^{\circ} 8$ (2014), pp. 339 y ss.; Lambourne, Wendy: "Transformative justice, reconciliation and peacebuilding”, en Buckley-Zistel, Susanne et al. (eds.) (2014): Transitional Justice Theories, Routledge, pp. 19 y ss. Esta autora incluye, en el concepto de justicia transformadora, cuatro elementos, a saber, la justicia penal o responsabilidad, la verdad como conocimiento y reconocimiento, la justicia socioeconómica y la justicia política (Ibid., pp. 23 y ss.).
} 
procesos transicionales, como la búsqueda de la verdad, la construcción de la paz y la fundación del nuevo orden jurídico y social. Pero cabe dudar de la capacidad de la justicia penal para cumplir con estos objetivos.

\subsection{Los fines tradicionales de la pena en contextos transicionales y posconflicto}

Los escenarios transicionales y posconflicto exigen un replanteamiento, al menos parcial, de los fines que tradicionalmente se encomiendas a la justicia penal ${ }^{69}$. Más allá de que la identificación de estos fines es objeto de un debate irresuelto, y posiblemente irresoluble ${ }^{70}$, los retos que el asunto plantea en los escenarios a los que nos referimos dependen de los rasgos peculiares de los crímenes a los que nos enfrentamos y, al mismo tiempo, de las características propias de los procesos transicionales ${ }^{71}$.

En primer lugar, la justicia penal en los escenarios posconflicto se enfrenta a episodios de violencia masiva, que afectaron a un enorme número de víctimas, y en los que participaron un gran número de responsables. Esto convierte en prácticamente imposible la persecución penal de todos los sujetos que, con distintas funciones y grados de responsabilidad, participaron en la comisión de los hechos. Si además combinamos esta circunstancia con la debilidad institucional que normalmente caracteriza los momentos de transición (especialmente en el ámbito jurisdiccional), el ejercicio de una persecución penal selectiva es una elección normalmente obligada. Por esta razón se han elaborado criterios de selección, que desempeñan la función de determinar el reparto de casos entre jurisdicciones internacionales e internas (como ocurre con el criterio de los "big fishes" o máximos responsables, aplicado por los Tribunales ad hoc y hasta previsto a nivel estatutario por el Tribunal Especial para Sierra Leona y por las Salas Extraordinarias en las Cortes de Camboya ${ }^{72}$ ) o bien, a nivel nacional, de identificar los casos que serán objeto de persecución penal (como ocurre con los criterios de selección y priorización de casos aplicados en Colombia ${ }^{73}$ ). Mientras que en el primer escenario la selectividad es un criterio jurisdiccional ${ }^{74}$ pero presupone siempre, al menos en principio, el ejercicio de la acción penal, en el segundo supuesto es más problemática porque implica admitir que algunos hechos quedarán exentos de persecución penal y castigo ${ }^{75}$.

\footnotetext{
${ }^{69}$ Seils, Paul: Squaring Colombia's Circle. The Objectives of Punishment and the Pursuit of Peace, ICTJ 2015, en https://www.ictj.org/publication/squaring-colombia-circle-objectives-punishment-peace, pp. 9-11.

${ }^{70}$ Para más detalles, véanse Rodríguez-Horcajo, op. cit., pp. 29-86 y Fletcher, George (2000): Rethinking Criminal Law, Oxford, OUP, pp. 414-420.

${ }^{71}$ Osiel, Mark (2010): "Why Prosecute? Critics of Punishment for Mass Atrocity", Human Rights Quarterly, n 22, pp. 118 y ss.; véase también Elster, Jon (2001): "Retribution in the Transition to Democracy", en Soeteman, Arend (ed.): Pluralism and Law, Springer, pp. 19 y ss.

${ }^{72}$ Art. 1 Estatuto del Tribunal Especial para Sierra Leone (“...persons who bear the greatest responsibility”) y Art. 2 Ley que establece las Salas Extraordinarias en las Cortes de Camboya ('... senior leaders of Democratic Kampuchea and those who were most responsible for the crimes').

${ }^{73}$ Esta política selectiva fue admitida, a nivel constitucional, por el Acto Legislativo 1/2012, "Marco Jurídico para la Paz", posteriormente desarrollada por la Fiscalía General de la Nación colombiana, Directiva 001/2012 de 4 de octubre, y actualmente se aplica en el Procedimiento de Justicia y Paz y en la Jurisdicción Especial para la Paz. Para mayor información, véanse, por ejemplo, las contribuciones en Gil Gil et al. (dirs.), Colombia como nuevo modelo, op. cit.; Aponte Cardona, Alejandro (2017): "El Acuerdo de paz y el modelo transicional colombiano: hacia un reconocimiento y dignificación de las víctimas", en Gil Gil y Maculan (dirs.), La influencia de las víctimas, op. cit., pp. 311-343; Idem: "Colombia”, op. cit., p. 235.

${ }^{74}$ Aunque esconda, en muchas ocasiones, razones políticas que responden a los intereses de las grandes potencias internacionales. Denuncian estos fines ocultos: Pastor, Daniel R. (2006): El poder penal internacional, Barcelona, Atelier, p. 88; Zolo, Danilo (2006): La giustizia dei vincitori. Da Norimberga a Baghdad, Roma, Laterza, pp. 33 y ss.

${ }^{75} \mathrm{La}$ selectividad es un dato constante (en algunos ordenamientos expresamente reconocido a través de la regla de la discrecionalidad de la Fiscalía, en otros en cambio como mero dato factual) en los sistemas penales nacionales, que no pueden hacer frente a todas y cada una de las infracciones penales que se realizan en un determinado Estado. No obstante, ese criterio suele excluir del ejercicio de la acción penal los crímenes objetivamente menos graves,
} 
Esta selectividad en la intervención punitiva del Estado, aun cuando se fundamente y regule con criterios racionales (como la gravedad o la naturaleza de los delitos, o la identificación de los máximos responsables, o la representatividad de los $\operatorname{casos}^{76}$ ), desafía el concepto ético de retribución ${ }^{77}$. La aplicación de la pena de manera desigual y parcial, efectivamente, choca con la retribución entendida como dar a cada uno su merecido, así como con la función de prevención negativa, pues permite que algunos criminales eviten la persecución penal y el castigo correspondiente.

Otro rasgo recurrente de esta fenomenología delictiva es su comisión por parte de grupos organizados o por verdaderos aparatos de poder, que se rigen por una jerarquía estricta y, normalmente, por una ideología (política, religiosa, o arraigada en otras creencias) muy fuerte y excluyente. Aunque estas circunstancias no sirvan para diluir la responsabilidad penal individual en una responsabilidad colectiva más difuminada, sí cabe preguntarse si, una vez que el aparato o grupo de referencia ha sido desmantelado, existe realmente el riesgo de que los criminales vuelvan a delinquir ${ }^{78}$.

Puede alegarse que no siempre los procesos de transición suponen la desaparición de las organizaciones implicadas en la comisión de los abusos, sino más bien su reconversión en grupos legítimos (por ejemplo, de grupos guerrilleros a partidos políticos reconocidos, o de dictaduras militares a Fuerzas Armadas comprometidas, al menos en principio, con la democracia $^{79}$ ) y su participación en el nuevo régimen. Pero incluso en estos casos, la profunda modificación del contexto que favoreció la violencia estructural, como por ejemplo el cese del conflicto armado, la disminución del poder que antes detentaban, la pérdida del apoyo de (parte de) la población, hacen realmente improbable que esos individuos vuelvan a cometer los mismos delitos que en el pasado. En cambio, allá donde estas circunstancias no han desaparecido y los criminales se siguen sintiendo amparados por las estructuras de poder a las que pertenecen, la imposición del castigo penal tampoco hace mucho, en realidad, para contribuir a su eliminación ${ }^{80}$. Lo que realmente se necesita en estos contextos son medidas de reforma institucional más amplias ${ }^{81}$.

Por último, la función reeducadora de la pena carece de sentido en relación con crímenes que no son el resultado de la conducta desviada de uno o unos sujetos, sino la consecuencia de

mientras que, en este tipo de situaciones, la selección se realiza entre crímenes que, en comparación con los delitos comunes, son todos graves.

${ }^{76}$ Para una comparación entre diferentes experiencias de aplicación de una política de selección y priorización de casos a nivel internacional y nacional, véase Bergsmo, Morten (ed.) (2010): Criteria for Prioritizing and Selecting Core International Crimes Cases, $2^{\mathrm{a}}$ ed., Torkel Opsahl Academic.

${ }^{77}$ Drumbl, Mark A. (2007): Atrocity, Punishment and International Law, Cambridge, CUP, pp. 151-154; Cryer, Robert (2014): “Aims, Objectives, Justifications of International Criminal Law", en Cryer, Robert et al., An Introduction to International Criminal Law and Procedure, $3^{\mathrm{a}}$ ed., Cambridge, CUP, p. 44.

${ }^{78}$ En términos similares, Ambos, Kai (2013): "Punishment without a Sovereign? The Ius Puniendi Issue of International Criminal Law: A First Contribution towards a Consistent Theory of International Criminal Law", Oxford Journal of Legal Studies, no 33, pp. 293 y ss.; Luban, David (2010): "Fairness to Rightness: Jurisdiction, Legality, and the Legitimacy of International Criminal Law", en Besson, Samantha y Tasioulas, John (eds), Philosophy of International Law, Oxford, OUP, p. 577; Teitel, Ruti (2000): Transitional Justice, Oxford, OUP, pp. 44 y ss.; Elster, Retribution, op. cit., pp. 28 y ss.

${ }^{79}$ En muchos países latinoamericanos donde se instalaron dictaduras militares, las Fuerzas Armadas fueron actores muy importantes de la transición a la democracia y mantuvieron cierto poder en el nuevo régimen, incluso sin haber previamente depurado sus organizaciones: así ocurrió en Argentina, Chile, Perú, Uruguay, como relatan los informes sobre estos países en Ambos et al. (coords.), Justicia de transición, op. cit.

${ }^{80}$ Eiroa, Pablo D. (2009): Políticas del castigo y derecho internacional. Para una concepción minimalista de la justicia penal, Buenos Aires: Ad Hoc, p. 165; Malamud-Goti, Jaime: "Transitional Government in the Breach: Why Punish State Criminals?", Human Rights Quarterly, no 12 (1990), p. 9.

${ }^{81}$ Cryer, op. cit., p. 43; Roth-Arriaza, Naomi (1995): Impunity and Human Rights in International Law and Practice, Oxford, OUP, p. 14. 
la actividad de instituciones distorsionadas y pervertidas en auténticas organizaciones criminales $^{82}$ o de un contexto extraordinario generado por un conflicto intercomunitario. La sistematicidad de estos crímenes requiere una respuesta que combine las sanciones dirigidas a los individuos con medidas estructurales más amplias, es decir, reformas institucionales y/o sociales que eliminen, o al menos reduzcan, las razones en las que se arraigaban la ideología del sistema criminal y los conflictos ${ }^{83}$.

Ante el cuestionamiento de los fines tradicionales de la justicia penal que los escenarios de transición imponen, y que aquí se ha resumido brevemente, quizás el único que mantiene su validez es el de protección de los bienes jurídicos a través de la prevención general positiva en su dimensión integradora ${ }^{84} \mathrm{o}$, utilizando términos de la tradición anglosajona, a través de la función expresiva del castigo ${ }^{85}$. Desde esta perspectiva, el castigo penal expresa el reproche de la comunidad en relación con determinadas conductas, confirmando a la vez la validez de las normas y restaurando la confianza en ellas ${ }^{86}$. De esta manera se pretende prevenir nuevos ataques en el futuro contra esas normas y esos bienes jurídicos ${ }^{87}$.

La función expresiva así descrita se manifiesta de dos maneras distintas: en primer lugar, la simple existencia de la ley, al prohibir determinadas conductas y al amenazar la imposición de un castigo para los que las cometan, cumple con la función de informar sobre el comportamiento prohibido y de expresar el valor del bien jurídicos protegido contra esas conductas. En segundo lugar, la misma función se manifiesta en la aplicación de la justicia penal, a su vez articulada en tres distintas fases. El núcleo central del mensaje de reproche se expresa en el ritual del proceso penal, es decir, cuando el acusado se sienta en el banquillo y se enfrenta a la acusación y al juez, y en la sentencia que cierra este procedimiento declarando, en su caso, su responsabilidad. Para ello, un requisito previo ineludible es la legitimidad de las instituciones que mandan este mensaje, que deriva de su composición y creación para garantizar su independencia, a la vez que de su compromiso real con las garantías de defensa y los estándares del juicio justo, según lo que un autor ha brillantemente resumido en el lema "fairness to rightness" $"$. La segunda fase en la que se expresa el mensaje de reproche es la imposición de la condena, que, en nuestra opinión, desempeña una función expresiva propia, al reflejar la gravedad del hecho y el grado de culpabilidad: cuanto más grave el hecho (o cuanto más intensa la culpabilidad), mayor la pena que se impone. Por último, esta función comunicativa se desarrolla también en la fase de ejecución de la pena, donde se confirman la importancia del mensaje de reproche y la gravedad del acto, otorgándole un contenido tangible.

\footnotetext{
${ }^{82}$ Malamud-Goti, op. cit., p. 10.

${ }^{83}$ De manera similar, Eiroa destaca que la rehabilitación de los condenados, concebida como un proceso de reforma interna, implícitamente niega el contexto, los factores estructurales de la violencia en que ése actuó: Eiroa, op. cit., p. 197.

${ }^{84}$ Ambos, Kai (2013): Treatise of International Criminal Law. Vol. I: Foundations and General Part, Oxford, OUP, p. 72.

${ }^{85}$ El resurgimiento de estas teorías empezó con el trabajo de Feinberg, Joel (1970): “The Expressive Function of Punishment”, en Idem, Doing and Deserving, Princeton University Press, p. 95. Para una visión más completa sobre estas teorías, véase Anderson, Elizabeth S. y Pildes, Richard (2000): "Expressive Theories of Law: a General Restatement", University of Pennsylvania Law Review, no 148, pp. 1503 y ss.

${ }^{86}$ Maculan, Elena (2017): "Fines de la pena y del proceso penal en contextos de transición", en Gil Gil y Maculan (dirs.): La influencia de las víctimas, op. cit., p. 207.

${ }^{87}$ Gil Gil, Alicia (2002): "Prevención general positiva y función ético-social del derecho penal”, en Díez Ripollés, José Luis (dir.), La ciencia del derecho penal ante el nuevo siglo: libro homenaje al profesor doctor don José Cerezo Mir, Madrid, Tecnos, pp. 9 y ss. Esta postura se enmarca en las teorías unitarias o mixtas de la pena, que combinan la retribución (entendida como la confirmación de la validez de la norma y de los bienes jurídicos) y la prevención negativa, que admitimos, junto con la prevención general, como fin de la pena.

${ }^{88}$ Luban, op. cit., p. 582.
} 
Ahora bien, cuando una de estas fases queda eliminada, total o parcialmente, ello no perjudica, en principio, la consecución de este objetivo comunicativo. Es lo que ocurre, en la mayoría de los casos, en los escenarios transicionales y posconflicto, en los que, como se ha recordado, existen prioridades y exigencias específicas, como el alcanzar un acuerdo de paz o mantenerlo, el involucrar a los criminales en el esclarecimiento de lo ocurrido y en la reparación a las víctimas, o el evitar un nuevo estallido de violencia. Los contextos de transición deben buscar un equilibrio entre estos objetivos contingentes y la pretensión de persecución penal y sanción de los crímenes del pasado o, visto desde otra perspectiva, entre soluciones de corto plazo y aspiraciones de largo plazo. Una correcta gestión de esta tensión intrínseca implica considerar los objetivos y los mecanismos transicionales como algo dinámico ${ }^{89}$ que debe someterse a un ejercicio de ponderación ${ }^{90}$.

Como resultado de esta ponderación, se suele adoptar una flexibilización de la persecución penal en al menos una de las tres fases antes recordadas. Así, consideraciones políticas acerca de los fines propios del proceso transicional pueden llevar a la extinción de la pena por medio de un indulto, a su suspensión, a su limitación o sustitución por otra clase de medidas. Un ejemplo lo tenemos en la experiencia de Irlanda del Norte, con los early releases permitidos en el marco del Good Friday Agreement de $1998^{91}$. Pero también pueden afectar a la fase anterior del procedimiento, es decir, la imposición de condena, permitiendo una pena menor que aquella proporcionada a la gravedad del delito y al grado de culpabilidad. Al respecto, podemos recordar las penas alternativas previstas en el Procedimiento de Justicia y Paz que se está llevando a cabo en Colombia, a partir de la Ley 975/2005 $5^{92}$. Las modificaciones en la condena o en su ejecución pueden también responder a consideraciones de prevención especial, pues la participación de los acusados en actividades de búsqueda de la verdad y/o en mecanismos de reparación muestran su potencial para la resocialización y la correspondiente disminución de la necesidad de castigo.

Por último, cabe plantearse la posibilidad, en los contextos transicionales y posconflicto, de medidas que eliminan o suspenden, al menos parcialmente, el proceso penal, con base en consideraciones políticas. El mecanismo más conocido en este sentido son las amnistías, cuya admisibilidad ante la comisión de graves violaciones de derechos humanos sigue siendo objeto de un candente debate, tanto en la doctrina especializada, como en la jurisprudencia internacional. Por un lado, está la doctrina de la Corte Interamericana de Derechos Humanos que, desde el caso Barrios Altos, ha ido afirmando la prohibición de amnistías, en un primer

\footnotetext{
${ }^{89}$ Leebaw, Bronwyn (2008): "The Irreconciliable Goals of Transitional Justice”, Human Rights Quarterly, n” 30, p. 118.

${ }^{90}$ Gil Gil, "El tratamiento jurídico", op. cit., p. 36.

${ }^{91}$ Esta medida, cuya concesión era decidida por un órgano independiente creado en 1998 y llamado Sentence Review Commission, se aplicó a personas que estaban cumpliendo condena por delitos políticos y conexos cometidos antes de la firma del Acuerdo, siempre que se cumplieran una serie de condiciones. Véase Campbell, Colm et al. (2003): "The frontiers of Legal Analysis: Reframing the Transition in Northern Ireland", Modern Law Review, no 66, pp. 317 y ss.

${ }^{92}$ Esta ley prevé la imposición de una pena reducida, que consiste de la privación de libertad por un tiempo de entre cinco y ocho años, además de un periodo adicional de libertad condicional (Art. 29 de la Ley 975/2005), para los miembros de grupos armados ilegales que se desmovilicen, rindan una versión libre sobre los hechos de los que tengan conocimiento y contribuyan con sus bienes a la reparación para las víctimas. Véase al respecto Huber, Florian (2007): La Ley de Justicia y Paz: desafíos y temas de debate, Bogotá, Friedrich Ebert Stiftung. Una sanción similar, que implica la privación de libertad por un tiempo de entre cinco y ocho años, la prevé también la Jurisdicción Especial para la Paz creada por el Acuerdo de paz de 2016 entre el Gobierno colombiano y las FARCEP. En este marco, se aplica a los delincuentes que declaren su responsabilidad cuando ya se ha abierto una investigación sobre ellos, pero antes de que empiece el proceso penal, mientras que, para aquellos que presten esta declaración antes de que empiece la investigación también, se aplica una sanción propia que conlleva una restricción de libertad, pero no la privación de la misma, junto con la obligación de llevar a cabo actividades con contenido restaurativo. Véase al respecto Maculan, "El proceso de paz colombiano", op. cit., pp. 53 y ss.
} 
momento, de manera limitada a las auto-amnistías, y posteriormente, a toda clase de amnistía, aun cuando hayan sido aprobadas por un Parlamento democrático y confirmadas por referéndum, y a los indultos y medidas similares que impidan la persecución penal ${ }^{93}$. Por otro lado, el Tribunal Europeo de Derechos Humanos ha mantenido, tradicionalmente, una postura más flexible ${ }^{94}$, aunque hay buenas razones para creer que este órgano va camino de una interpretación más cercana a su homólogo interamericano ${ }^{95}$. Según esta visión más flexible, a la que nos sumamos, no deberían excluirse de manera absoluta estas medidas de los escenarios de transición, sino valorar caso por caso su admisibilidad, tomando en consideración el órgano que las aprueba y el procedimiento correspondiente, las condiciones a las que se someten los beneficios que otorgan y la legitimidad de sus fines en ese específico contexto social ${ }^{96}$.

Si defendemos la admisibilidad, en los escenarios transicionales, de estas medidas que excluyen o limitan la persecución penal, como se sugiere aquí, entonces la función expresiva que normalmente se encomienda al proceso penal podría ser desempeñada, en estos casos, por otros mecanismos que consiguen dar un mensaje de estigmatización y de reafirmación de los valores sociales vulnerados. Aunque históricamente el ritual del proceso penal haya sido elegido como el lugar más adecuado para cumplir con esa función, en los contextos de transición, y debido precisamente a la naturaleza excepcional de estos, otros mecanismos pueden enviar el mismo mensaje de manera satisfactoria. Ello siempre que cumplan con unos requisitos mínimos de legitimidad y fairness similares a aquellos que regulan el proceso penal ${ }^{97}$. En este sentido, la experiencia de la Truth and Reconciliation Commission sudafricana ofrece un modelo, al menos relativamente exitoso, de sustitución del proceso penal por una declaración pública de responsabilidad ante una comisión de la verdad, que tenía además el poder de conceder amnistías individuales ${ }^{98}$.

En todo caso, hay que reconocer debidamente las especificidades y las necesidades de cada comunidad y admitir, en su caso, una revisión de los conceptos tradicionales (al menos en nuestros ordenamientos de tradición occidental) de comprobación de la responsabilidad y de castigo, en la medida en que estos no se condicen con las circunstancias de un particular

\footnotetext{
${ }^{93}$ Corte Interamericana de Derechos Humanos, caso Barrios Altos v. Perú, Serie C n ${ }^{\circ} 75$, sentencia, 14 de marzo de 2001, párrs. 41-43; Gelman v. Uruguay, Serie C nº 221, sentencia, 24 de febrero de 2011; Barrios Altos y La Cantuta v. Perú, "Supervisión de cumplimiento de sentencia", 30 de mayo de 2018. Aun así, la Corte parece ser más flexible cuando se enfrenta a situaciones de conflicto armado todavía en curso: véase Masacre de El Mozote v. El Salvador, Serie C no 252, 25 de octubre de 2012. Para un examen más profundo, véase, por ejemplo, Mallinder, Louise (2016): "The End of Amnesty or Regional Overreach? Interpreting the Erosion of South America's Amnesty Laws", International and Comparative Law Quarterly, nº 65, pp. 645 y ss.

${ }_{94}$ Tribunal Europeo de Derechos Humanos, Ould Dahl v. France, App. No 13113/03, 17 de marzo de 2009. En una sentencia más reciente el Tribunal ha reconocido "una tendencia creciente en el Derecho internacional a considerar inaceptables esas amnistías”: Marguš v. Croacia, App. № 4455/10, 13 de noviembre de 2012, párr. 139. Véase, para más detalles, Maculan, Elena (2018): "Derecho penal, obligaciones internacionales y justicia de transición”, Revista penal, no 41, pp. 117 y ss.

${ }^{95}$ Así Jackson, Miles: “Amnesties in Strasbourg”, Oxford Journal of Legal Studies, vol. 38, no 3 (Autumn 2018), p. 1. Véase también Seibert-Fohr, op. cit., pp. 51 y ss. y 105 y ss.

${ }_{96}$ Maculan, "Derecho penal, obligaciones internacionales", op. cit.

${ }^{97}$ Freeman, op. cit., pp. 88 y ss. En contra, Osiel, op. cit., pp. 134-137, que destaca los límites de las comisiones de la verdad como alternativas al proceso penal.

${ }^{98} \mathrm{La}$ amnistía aplicada en esa experiencia transicional era democrática, bilateral y condicional, pues podía concederse (solo por delitos políticos, aun cuando constituyeran graves violaciones de derechos humanos) a cambio de la declaración pública de responsabilidad por parte de los delincuentes y de su contribución para averiguar lo ocurrido. Este mecanismo permitía combinar la justicia (entendida aquí como responsabilidad, en sentido no estrictamente penal) con los objetivos de verdad y reconciliación. Véanse Andrea Lollini, op. cit.; Du Bois-Pedain, op . cit.'
} 
momento histórico como es el proceso transicional. Nos remitimos en este sentido a la idea de "pluralismo cosmopolita" propuesta por Drumbl".

\subsection{Los fines específicos de la justicia penal en los contextos transicionales y posconflicto}

Más allá de la revisión de los fines tradicionales de la justicia penal, las experiencias transicionales también muestran una tendencia a sobrecargar el ámbito penal con unos objetivos ulteriores, directamente relacionados con el contexto peculiar en el que se encuentran. Nos referimos a la averiguación de la verdad, a la reconciliación y a la construcción de la paz y/o a la consolidación del ordenamiento. No obstante, ante un análisis más atento, la justicia penal no resulta el mecanismo más adecuado para conseguir estos fines.

En primer lugar, el proceso penal es considerado por muchos actores transicionales como una herramienta privilegiada y necesaria para la averiguación de la verdad acerca de la experiencia de violencia, que a su vez constituye no solamente un elemento indispensable para la superación del pasado conflictivo y para la no repetición, sino también un derecho de las víctimas que surge a raíz de la comisión de crímenes masivos y que constituye uno de los pilares de la proclamada triada de fines de la justicia transicional (verdad, justicia y reparación) ${ }^{100}$.

Debido a que la sentencia tiene que basarse en hechos probados más allá de toda duda razonable, requiere un riguroso trabajo de documentación y reconstrucción de los mismos que efectivamente aporta una contribución importante a la averiguación de lo ocurrido ${ }^{101}$. Además, el proceso ofrece un foro público en el que la verdad así alcanzada es declarada de manera oficial por órganos (los tribunales) cuya legitimación está, al menos en principio, consolidada $^{102}$.

Sin embargo, cabe recordar la distinción entre verdad procesal y verdad histórica o material, sobre la cual muchos y brillantes autores han escrito ${ }^{103}$. La primera es inevitablemente limitada, por un lado, porque se centra en la conducta del presunto criminal y en sus efectos lesivos, sin detenerse en el contexto que llevó a la comisión del crimen y en sus raíces profundas ${ }^{104}$. Por el otro lado, la propia estructura del proceso penal impide llegar a una verdad absoluta en aras del respeto de las garantías fundamentales de defensa. La presunción de inocencia, el principio in dubio pro reo, la carga de la prueba que recae en la acusación, la llamada cross-examination, todas estas garantías actúan a la vez como límite en la averiguación de la verdad, y lo mismo puede decirse de la res judicata, que otorga un carácter definitivo e inmodificable (salvo circunstancias muy excepcionales) a lo determinado en el proceso, lejos del carácter siempre abierto y plural que tienen las investigaciones históricas ${ }^{105}$.

\footnotetext{
${ }^{99}$ Drumbl, op. cit.

${ }^{100}$ Bassiouni, "Victims' Rights", op. cit.; Doak, Jonhatan (2008): Victims' Rights, Human Rights and Criminal Justice, Sydney, Hart, pp. 180 y ss.; Chinchón Álvarez, op. cit., pp. 235 y ss.

${ }^{101}$ Malamud-Goti, op. cit., p. 11.

102 Duff, Antony R.: "Process, not Punishment: The importance of Criminal Trials for Transitional and Transnational Justice”, Minnesota Legal Studies Research Paper, ${ }^{\circ} 14$ (2014),p. 10. en http://papers.ssrn.com/sol3/papers.cfm?abstract_id=2387601

${ }^{103}$ Para una reflexión sobre este tema, en relación con la emersión del llamado derecho a la verdad de las víctimas de graves violaciones de derechos humanos, véase, también para referencias ulteriores: Pastor, Daniel (2013): "Acerca de la verdad como derecho y como objeto exclusivo del proceso penal", en Maculan, Elena y Pastor, Daniel, El derecho a la verdad y su realización por medio del proceso penal, Buenos Aires, Hammurabi, pp. 19 y ss.

${ }^{104}$ Bassiouni, M. Cherif (2002): "Accountability for Violations of International Humanitarian Law and Other Serious Violations of Human Rights", en Idem (ed.): Post-Conflict Justice, Transnational, p. 400.

105 Pastor, "Acerca de la verdad", op. cit., pp. 92 y ss.; Weigend, Thomas: "Is the criminal process about truth? A German perspective", Harvard Journal of Law and Pubic Policy, n 26 (2003), pp. 157 y ss. Otros autores, en cambio, defienden que el proceso penal es el lugar perfecto para cumplir con la tarea de averiguación de la verdad: véase por ejemplo Taruffo, Michele (2015): "Verità e giustizia di transizione", Criminalia (2015), pp. 21 y ss.
} 
La consolidación de estas reglas ha llevado a una transformación hasta en los sistemas procesales inquisitorios, en los que la averiguación de la verdad sobre los hechos tradicionalmente se ha considerado una prioridad, a diferencia de los sistemas acusatorios, que se centran en la confrontación entre las partes y entre sus respectivas verdades ${ }^{106}$. Pero la paulatina desaparición de las diferencias entre estos dos modelos puros y la creación de distintos tipos de sistemas procesales híbridos, así como la consolidación de los estándares del juicio justo como derechos humanos reconocidos y protegidos por el Derecho internacional, han llevado a una aceptación prácticamente universal de límites procesales a la tarea de averiguación de la verdad llevada a cabo por los procesos penales.

Por tanto, una investigación exhaustiva acerca de la experiencia de violencia colectiva puede sin duda beneficiarse de la contribución de los tribunales penales, pero no puede limitarse a ella: debe ser complementada por otros mecanismos que no estén sujetos a los límites estrictos aplicados en esa jurisdicción, para ofrecer una reconstrucción de los hechos lo más amplia y completa posible, como comisiones de la verdad o comisiones de investigación ${ }^{107}$.

En segundo lugar, la persecución penal se interpreta a menudo como una etapa indispensable para cumplir con el fin de reconciliación social, uno de los objetivos centrales de todo proceso transicional. Sin embargo, en nuestra opinión el proceso penal, cuya estructura reproduce el conflicto en un ritual formalizado y controlado ${ }^{108}$, no favorece exactamente el encuentro entre víctima y delincuente, sino que, por el contrario, reitera el conflicto entre ellos. Es cierto que el proceso penal promueve un reconocimiento de los criminales y de las víctimas como miembros de la comunidad política, y que esto a su vez puede contribuir a reconstruir un nivel mínimo de coexistencia en la sociedad ${ }^{109}$. Pero se trata de un reconocimiento puramente formal, mientras que el objetivo de una reconciliación más profunda entre víctimas y criminales requiere acudir a otros mecanismos, especialmente, los de la justicia restaurativa, que favorezcan un diálogo incluyente entre las partes y la restauración de sus relaciones interpersonales. Además, a nivel macro, la reconciliación social pasa por la adopción de medidas políticas, económicas, educativas, dirigidas a eliminar la división entre los distintos grupos sociales. Por el contrario, una persecución penal ejercida con una perspectiva retribucionista y maximalista plantea el riesgo de convertirse en un poderoso factor de exclusión de los criminales, que seguirían siendo tratados como "los otros", el enemigo, en contra de los mencionados objetivos de reconciliación social ${ }^{110}$.

En tercer lugar, una idea que ha ido difundiéndose de la mano del lema "no hay paz sin justicia" 111 es que la justicia penal en contextos transicionales, a través del castigo ejemplar de los crímenes cometidos durante el conflicto, es un ingrediente fundamental para la construcción

\footnotetext{
106 Weigend, Thomas: "Should We Search for the Truth, and Who Should Do it", North Carolina Journal of International Law and Commercial Regulation, $\mathrm{n}^{\circ} 36$ (2010), pp. 389 y ss.; Grande, Elisabetta (2008): "Dances of Criminal Justice: Thoughts on Systemic Differences and the Search for the Truth", en Jackson, John et al. (eds.), Crime, Procedure and Evidence in a Comparative and International Context, Oxford, Hart Publishing, p. 147.

${ }^{107}$ Freeman, op. cit., pp. 40-69.

${ }^{108}$ Garapon, Antoine (2001): Bien juger. Essai sur le rituel judiciaire, Paris, Odile Jacob.

${ }^{109}$ Duff, op. cit., p. 7.

${ }^{110}$ Luban, op. cit., p. 579; Eiroa, op. cit., pp. 205 y ss.

111 Este lema aparece en los instrumentos que fundaron los Tribunales penales internacionales ad hoc (Considerando 9, Resolución n ${ }^{\circ}$ 808/1993 del Consejo de Seguridad de NNUU, de 22 de febrero, costitutiva del Tribunal Penal Internacional para la antiguas Yugoslavia ; Considerando 7, Resolución n 955/1994, del Consejo de Seguridad de NNUU, de 8 de noviembre, costitutiva del Tribunal Penal Internacional para Ruanda) y en toda la retórica que rodea su legitimación: Zolo, Danilo : "Peace through Criminal Law?", Journal of International Criminal Justice, nº 2 (2002), p. 729.
} 
de la paz $^{112}$. Otros autores hacen hincapié en la función constituyente que la justicia penal en estos contextos, en aras de la creación de un nuevo orden jurídico ${ }^{113}$. A través de la firme condena de la violencia del pasado, el proceso penal restaura los intereses sociales y las normas vulneradas durante esa experiencia, marcan la separación entre el régimen actual y el previo y promueven la confianza ciudadana en el nuevo orden social ${ }^{114}$. De esta manera, la justicia penal cumple con una tarea transformadora y fundacional, dirigida al restablecimiento del Estado democrático de derecho ${ }^{115}$.

En realidad, ambas teorías representan, en nuestra opinión, una derivación de las teorías de prevención general positiva en los específicos contextos transicionales. La contribución que proporciona la justicia penal a la construcción del nuevo orden jurídico y social y de una paz estable y duradera es, simplemente, un efecto indirecto de las funciones de estigmatización, comunicación y reafirmación de las normas vulneradas que la persecución penal normalmente cumple, y no parece necesario clasificar esos objetivos como fines propios de la justicia penal.

Al mismo tiempo, la persecución penal es de por sí insuficiente para alcanzar ese objetivo fundacional: de manera similar a lo que ocurre con la reconciliación social, se necesitan otras medidas complementarias, como mecanismos de justicia restaurativa, planes educativos, reformas institucionales y programas de capacitación ${ }^{116}$.

Además, en determinadas circunstancias el ejercicio de la persecución penal puede convertirse casi en un obstáculo para la consecución de los objetivos de fundación y consolidación de las nuevas instituciones ${ }^{117}$, especialmente cuando los que cometieron los delitos en el pasado retienen todavía un cierto grado de poder en el nuevo régimen ${ }^{118}$. La prioridad misma de poner fin a un conflicto armado requiere a menudo hacer concesiones, como por ejemplo imponer una pena reducida o penas alternativas, de tal manera que los responsables de los crímenes tengan un incentivo para participar en el proceso de desarme ${ }^{119}$.

Por último, los objetivos de reconciliación y consolidación del nuevo orden jurídico y social pueden alcanzarse también con una persecución penal limitada ${ }^{120}$ (por ejemplo, con una selección y priorización de los casos a perseguir), combinada con otros mecanismos alternativos o complementarios. En este sentido, la amnistía condicional aplicada por la Truth and Reconciliation Commission sudafricana, a cambio de una declaración pública de responsabilidad por parte de los que cometieron delitos políticos, cumplió una verdadera función constituyente en ese país ${ }^{121}$.

\footnotetext{
112 Véase Schirch, Lisa: "Linking Human Rights and Conflict Transformation. A Peacebuilding Framework", en Mertus, Julie y Helsing, Jeffrey (eds.) (2006): Human Rights and Conflict. Exploring the Links between Rights, Law and Peacebuilding, New York, UN Institute for Peace Press, pp. 63 y ss.

113 Teitel, op. cit., pp. 49-51.

${ }^{114}$ Malamud-Goti, op. cit., pp. 11-12.

115 Teitel, op. cit., p. 30.

${ }^{116}$ Clark, Janine N. (2011): "Peace, Justice and the International Criminal Court: Limitations and Possibilities", Jouranl of International Criminal Justice, vol. 9, no 3, pp. 521 y ss.; Eiroa, op. cit., p. 143.

${ }^{117}$ Como sugiere Eiroa, Pablo D. (2017): "El impacto de las jurisdicciones penales internacionales en la finalización de un conflicto de violencia grave y la consolidación de la paz", en Gil Gil y Maculan (dirs.), $L a$ influencia de las víctimas, op. cit., pp. 81 y ss. Véase también Broache, Michael (2016): "Irrelevance, Instigation and Prevention: The Mixed Effects of International Criminal Court Prosecutions on Atrocities in the CNDP/M23 Case", International Journal of Transitional Justice, $\mathrm{n}^{\circ} 10$, pp. 388 y ss.

118 Malamud-Goti, op. cit., p. 14.

${ }^{119}$ En términos similares, el voto en disidencia del juez García Sayán en Corte Interamericana de Derechos Humanos, El Mozote v. El Salvador, Serie C no 252, sentencia, 25 de octubre 2012, párrs. 30-31.

120 Teitel, op. cit., p. 49.

${ }^{121}$ Lollini, op. cit., pp. 95 y ss.
} 
En conclusión, no estamos sugiriendo que hay que renunciar completamente al ejercicio de la persecución penal, sino que, en los contextos extraordinarios de transición, debería permitirse una flexibilización de la intervención punitiva del Estado, cuando esta última constituya un obstáculo, más que una contribución, para la consecución de la paz. De acuerdo con esta visión, el lema que con frecuencia se invoca en la justicia de transición (no hay paz sin justicia) debería reformularse con el más realista "tanta justicia (penal) cuanta paz permita"122.

\section{Reflexiones conclusivas}

Las diversas experiencias históricas nos muestran que no existe un único modelo de justicia transicional válido y aplicable a cualquier experiencia de violencia colectiva. Por el contrario, desde la teorización de la justicia transicional solo es posible elaborar una serie de principios y fines deseables, y recomendar un conjunto de herramientas a disposición de los Estados, que debería elegir los mecanismos transicionales adaptándolos a la coyuntura social y política del conflicto particular.

Sin embargo, en tiempos recientes, se ha ido afianzando la idea de que la pena retributiva de los criminales es un mecanismo para dar satisfacción a las víctimas y hasta un derecho de estas, a la vez que el medio más adecuado para conseguir la paz y la construcción del nuevo orden social. La justicia penal y la pena se convertirían así es un ingrediente esencial de los procesos de transición y posconflicto. Por el contrario, en este artículo se ha querido mostrar que semejante interpretación sobrecarga la justicia penal con objetivos que esta no está capacitada para cumplir, o que pueden alcanzarse de manera más satisfactoria a través de otros mecanismos.

En relación con los beneficios que el castigo penal proporciona a las víctimas, un análisis crítico de las distintas teorías de la pena en las que se fundamenta esta idea lleva a concluir que la pena, entendida como imposición de un mal, puede explicarse racionalmente solo por su efecto preventivo, actuando la retribución como límite a las exigencias preventivas. Así, en nuestra opinión, las teorías que pretenden justificar la necesidad de imponer un mal al delincuente con base en sus efectos beneficiosos para las víctimas, o en su efecto de poner fin al daño causado a ellas, constituyen nada más que un intento de racionalizar el deseo de reciprocidad de las víctimas (o su deseo de venganza, utilizando este término en sentido no peyorativo $^{123}$ ).

Consideramos que no se puede negar que el castigo penal puede tener efectos beneficiosos para las víctimas, como demostrar públicamente la injusticia padecida y ofrecer ciertas garantías de no repetición. De esta manera se puede satisfacer el deseo de justicia de las víctimas, restaurar su confianza en el sistema jurídico quebrantado y contribuir a evitar su desocialización. Pero no debe olvidarse que esos sentimientos de justicia, que son el resultado de la estandarización de una reacción evolutiva positiva, se fundamentan en el mecanismo de reciprocidad que, a su vez, sirve para la conservación del grupo y del individuo como entidades sociales. El castigo es un instrumento preventivo y la retribución establece un límite al quantum de pena, al requerir sanciones proporcionadas, en el sentido de que no se sobrepase la pena

\footnotetext{
${ }^{122}$ Malarino, Ezequiel (2013): “Transición, derecho penal y amnistía. Reflexiones sobre la utilización del derecho penal en procesos de transición", Revista de Derecho Penal y Criminología, no 9, p. 211. Esta propuesta difiere también de otra, que puede resumirse en el lema "Primero paz, luego justicia", que no renuncia al elemento justicia pero lo difiere a un momento posterior en el que la paz se haya estabilizado. No obstante, una secuencia similar no parece posible de programar, pues ningún líder estaría dispuesto a negociar para poner fin a un conflicto sabiendo de antemano que los beneficios que pudieran derivarle de esa negociación (como una amnistía) tienen, por así decirlo, fecha de caducidad. Además, una solución de este tipo plantea serios problemas para el principio de irretroactividad penal, pues se aplicaría de manera retroactiva una nueva ley que reactiva una responsabilidad previamente anulada o suspendida, sin duda más desfavorable para el reo.

${ }^{123}$ Prittwitz, op. cit., p. 129; Silva Sánchez, "Una crítica a las doctrinas penales”, op. cit., p. 56.
} 
adecuada a lo injusto culpable por necesidades preventivas. Pero la pena proporcionada, la pena retributiva, puede ser reducida si las exigencias de prevención son menores o si otros intereses en juego lo reclaman. Por ello no puede obviarse el carácter instrumental del castigo e invocarse este como un fin en sí mismo, y el llamado derecho a la justicia de las víctimas no debe sustituir el fin de la justicia penal, que es la protección de los bienes jurídicos a través de la función preventiva.

El Estado, con su monopolio de la violencia, puede controlar los instintos y deseos de reciprocidad de las víctimas, de por sí comprensibles y legítimos, y ponerles límites racionales. Y la concesión de un tratamiento más beneficioso en ámbito penal (en la forma de penas reducidas o alternativas, como se ha recordado), a cambio de la desmovilización, confesión, declaración de responsabilidad y/o contribución a la reparación, si por un lado implica la renuncia a la pena "justa", en el sentido de proporcionada a la gravedad del delito y al grado de culpabilidad del criminal, por el otro cumple con otros objetivos que también constituyen intereses de las víctimas y de la sociedad, por ejemplo, la celeridad del procedimiento y de la condena y la contribución a la averiguación de la verdad, a la reparación y a la no repetición.

El Estado puede por tanto someter las pretensiones de castigo de las víctimas a un ejercicio de ponderación con otros fines y exigencias, en búsqueda de la mejor solución posible para mantener el orden social y la protección de los bienes jurídicos de una sociedad, y, en consecuencia, ofrecerles satisfacción a través de otros mecanismos (como comisiones de la verdad, excusas públicas, eventos oficiales de reconocimiento para las víctimas, memoriales, reparaciones materiales y simbólicas).

Desde la perspectiva de la sociedad en su conjunto, hemos argumentado que los contextos transicionales y posconflicto plantean la necesidad de repensar los fines clásicos de la justicia penal, debido tanto a los rasgos excepcionales propios de estos escenarios, como a la naturaleza masiva y normalmente sistemática de los crímenes cometidos durante experiencias de violencia colectiva. En estas situaciones, el fin que mantiene su centralidad es la prevención general positiva e integradora, pues la persecución penal con sus tres etapas (el proceso, la imposición de condena y su ejecución) sirve para expresar el rechazo de la comunidad hacia determinadas conductas, confirmando así los valores protegidos por el derecho penal, restaurando la confianza ciudadana en las normas y previniendo la comisión de delitos en el futuro. De esta manera, la justicia penal contribuye también, de manera indirecta, a la fundación y consolidación del nuevo orden jurídico y social a la construcción de una paz estable.

Por un lado, hay que reconocer la insuficiencia de la persecución penal per se para alcanzar estos objetivos, y la necesidad de complementarla con otras medidas de reforma, búsqueda, reparación y educación, en el marco de una idea de "justicia transformadora" mucho más amplia que la justicia penal ${ }^{124}$.

Por otro lado, las circunstancias propias del proceso transicional pueden, paradójicamente, convertir la persecución penal en un obstáculo, en vez de un instrumento, para el mantenimiento del orden social y la protección de los bienes jurídicos. Ello ocurre cuando el proceso penal y la pena, aplicados según un enfoque puramente retributivo y maximalista, desencadenan nuevos episodios de violencia o impiden poner fin a ella, alejan a los criminales de posibles iniciativas para la búsqueda de la verdad y la reparación y debilitan las nuevas instituciones.

En conclusión, nos parece importante recordar que la justicia penal como ius puniendi es un instrumento del Estado, no el único disponible, ni una obligación del mismo, para alcanzar el objetivo último de protección de los bienes jurídicos y garantía de una convivencia pacífica

\footnotetext{
${ }^{124}$ Lambourne, op. cit., pp. 23 y ss.
} 
entre los individuos que conforman una comunidad. De esta manera, hay que acudir a la justicia penal solo cuando y en la medida en que ella resulta útil y necesaria. Pero, cuando existen otros mecanismos que ofrecen esa protección, o cuando la justicia penal corre el riesgo, de ser aplicada, de constituir una amenaza para esos bienes jurídicos (porque desestabilizaría el sistema jurídico al que se encomienda esa protección), entonces hay que dar un paso atrás, y adaptar y limitar la persecución penal y sus consecuencias de acuerdo con las circunstancias específicas de cada caso.

\section{Bibliografía}

Ambos, Kai: "Punishment without a Sovereign? The Ius Puniendi Issue of International Criminal Law: A First Contribution towards a Consistent Theory of International Criminal Law", Oxford Journal of Legal Studies, no 33 (2013).

Ambos, Kai (2013): Treatise of International Criminal Law. Vol. I: Foundations and General Part, Oxford, OUP.

Ambos, Kai y Böhm, Laura: “Tribunal Europeo de Derechos Humanos y Corte Interamericana de Derechos Humanos ¿Tribunal tímido y tribunal audaz?”, en Ambos, Kai; Malarino, Ezequiel y Elsner, Gisela (coords.) (2011): Sistema interamericano de protección de los derechos humanos y derecho penal internacional, vol. II, Montevideo, KAS.

Ambos, Kai; Malarino, Ezequiel y Elsner, Gisela (coords.) (2010): Sistema interamericano de protección de los derechos humanos y derecho penal internacional, vol. I, Montevideo, KAS.

Ambos, Kai; Malarino, Ezequiel y Elsner, Gisela (coords.) (2011): Sistema interamericano de protección de los derechos humanos y derecho penal internacional, vol. II, Montevideo, KAS.

Anderson, Elizabeth S. y Pildes, Richard: "Expressive Theories of Law: a General Restatement", University of Pennsylvania Law Review, nº 148 (2000).

Aponte Cardona, Alejandro: "Colombia”, en Ambos, Kai; Malarino, Ezequiel y Elsner, Gisela (coords.) (2009): Justicia de transición, Montevideo, KAS.

Aponte Cardona, Alejandro: "El Acuerdo de paz y el modelo transicional colombiano: hacia un reconocimiento y dignificación de las víctimas", en Gil Gil, Alicia y Maculan, Elena (dirs.) (2017): La influencia de las víctimas en el tratamiento jurídico de la violencia colectiva, Madrid, Dykinson, pp. 311-343.

Arnoso Martínez, Maitane: "Violencia colectiva y creencias básicas sobre el mundo, los otros y el yo: impacto y reconstrucción”, en Páez Rovira, Darío et al. (coords.) (2011): Superando la violencia colectiva y construyendo una cultura de paz, Fundamentos.

Aureli, Filippo et al. (1992): "Kin-oriented redirection among Japanese macaques: an expression of a revenge system?", Animal Behaviour, no 44.

Bassiouni, M Cherif (2010): "Victims' Rights", en Idem (ed.), The Pursuit of International Criminal Justice: A World Study on Conflicts, Victimization, and Post-conflict Justice, vol. I, Cambridge, Intersentia.

Bassiouni, M. Cherif: "Accountability for Violations of International Humanitarian Law and Other Serious Violations of Human Rights”, en Idem (ed.) (2002): Post-Conflict Justice, Transnational. 
Bergsmo, Morten (ed.) (2010): Criteria for Prioritizing and Selecting Core International Crimes Cases, $2^{\mathrm{a}}$ ed., Torkel Opsahl Academic.

Bianchi, Herman (1994): Justice as Sanctuary: Toward a System of Crime Control, Bloomington, Indiana University Press.

Bornkamm, Paul C. (2012): Rwanda's Gacaca courts, Oxford, OUP.

Braithwaite, John (2002): Restorative Justice \& Responsive Regulation, Oxford, OUP.

Broache, Michael: "Irrelevance, Instigation and Prevention: The Mixed Effects of International Criminal Court Prosecutions on Atrocities in the CNDP/M23 Case", International Journal of Transitional Justice, $\mathrm{n}^{\circ} 10$ (2016).

Burgess, Patrick (2005): “Justice and reconciliation in East Timor", Criminal Law Forum, no 15 .

Campbell, Colm et al.: "The frontiers of Legal Analysis: Reframing the Transition in Northern Ireland", Modern Law Review, vol. 66, nº 3 (2003)

Caterina, Raffaele (2015): "La reciprocità: alle origini della vendetta e dello scambio", en Lorini, Giuseppe y Masia, Michelina (a cura di), Antropologia della vendetta, Napoli, ESI.

Cerezo Domínguez, Ana Isabel (2010): El protagonismo de las víctimas en la elaboración de las leyes penales, Valencia, Tirant lo Blanch.

Cerruti, Pedro: "Procesos emocionales y respuestas punitivas: acerca del activismo penal de las víctimas del delito", Revista Electrónica de Psicología Política, n. 20 (2009).

Chagnon, Napoleon: "Life Histories, Blood Revenge, and Warfare in a Tribal Population" Science, $\mathrm{n}^{\circ} 4843$ (1988), pp. 985-992.

Chinchón Álvarez, Javier (2007): Derecho internacional y transiciones a la democracia y la paz: Hacia un modelo para el castigo de los crímenes pasados a través de la experiencia iberoamericana, Sevilla, Parthenos.

Clamp, Kerry (ed.) (2016): Restorative Justice in Transitional Settings, Routledge.

Clark, Janine N.: "Peace, Justice and the International Criminal Court: Limitations and Possibilities”, Journanl of International Criminal Justice, vol. 9, nº 3 (2011).

Cryer, Robert: "Aims, Objectives, Justifications of International Criminal Law", en Cryer, Robert et al.(2014): An Introduction to International Criminal Law and Procedure, $3^{\mathrm{a}}$ ed., Cambridge, CUP.

Doak, Jonhatan (2008): Victims' Rights, Human Rights and Criminal Justice, Sydney, Hart.

Drumbl, Mark A. (2007): Atrocity, Punishment and International Law, Cambridge, CUP.

Du Bois-Pedain, Antje (2007): Transitional Amnesty in South Africa, Cambridge, CUP.

Duff, Antony R. : "Process, not Punishment: The importance of Criminal Trials for Transitional and Transnational Justice", Minnesota Legal Studies Research Paper, $\mathrm{n}^{\circ} 14$ (2014) en http://papers.ssrn.com/sol3/papers.cfm?abstract_id=2387601.

Durán Migliardi, Mario: “Teorías absolutas de la pena: origen y fundamentos. Conceptos y críticas fundamentales a la teoría de la retribución moral de Immanuel Kant a propósito del neoretribucionismo y del neo-proporcionalismo en el derecho penal actual", Revista de Filosofía, $\mathrm{n}^{\circ} 67$ (2011).

Durkheim, Émile (2008) : De la division du travail social, Paris, Les Presses Universitaires de France. 
Echeburúa, Enrique et al. : "Evaluación del daño psicológico las víctimas de delitos violentos", Psicopatología clínica, legal y forense, vol. 4, nº 1-3 (2004).

Eiroa, Pablo D. (2009): Políticas del castigo y derecho internacional. Para una concepción minimalista de la justicia penal, Buenos Aires, Ad Hoc.

Eiroa, Pablo D.: "El impacto de las jurisdicciones penales internacionales en la finalización de un conflicto de violencia grave y la consolidación de la paz", en Gil Gil, Alicia y Maculan, Elena (dirs.) (2017): La influencia de las víctimas en el tratamiento jurídico de la violencia colectiva, Madrid, Dykinson.

Elster, Jon: "Retribution in the Transition to Democracy", en Soeteman, Arend (ed.) (2001), Pluralism and Law, New York, Springer.

Elster, Jon (2004): Closing the books. Transitional Justice in Historical Perspective, Cambridge, CUP.

Engle, Karen; Miller, Zinaida y Davis, Dennis (2016): Anti-impunity and the Human Rights Agenda, Cambridge, CUP.

Eser, Albin et al. (2001): Strafrecht in Reaktion auf Systemunrecht: Vergleichende Einblicke in Transitionsprozesse; ein Projektbericht, vol. 6, Freiburg i. Br., Iuscrim.

Feijoo Sánchez, Bernardo (2014): La legitimidad de la pena estatal, Madrid, Iustel.

Feinberg, Joel: "The Expressive Function of Punishment", en Idem (1970): Doing and Deserving, Princeton University Press.

Fletcher, George: "The Place of Victims in the Theory of Retribution", Buffalo Criminal Law Review, no 3 (1999).

Fletcher, George (2000): Rethinking Criminal Law, Oxford, OUP.

Fornasari, Gabriele (2014): "Giustizia di transizione (diritto penale)", en Enciclopedia del diritto, vol. VIII, Milano, UTET,.

Freeman, Mark (2006): Truth Commissions and Procedural Fairness, Cambridge, CUP.

Galáin Palermo, Pablo: “Uruguay”, en Ambos, Kai; Malarino, Ezequiel y Elsner, Gisela (eds.) (2009): Justicia de transición, Montevideo, KAS.

Garapon, Antoine (2001): Bien juger. Essai sur le rituel judiciaire, Paris, Odile Jacob.

Gert, Heather et al.: "Hampton on the Expressive Power of Punishment", Journal of Social Philosophy, vol. 35, $\mathrm{n}^{\circ} 1$ (2004).

Gibson, James L.: "Truth, Justice, and Reconciliation: Judging the Fairness of Amnesty in South Africa", American Journal of Political Science, no 46 (2002).

Gil Gil, Alicia (2002): "Prevención general positiva y función ético-social del derecho penal”, en Díez Ripollés, José Luis (dir.), La ciencia del derecho penal ante el nuevo siglo: libro homenaje al profesor doctor don José Cerezo Mir, Madrid, Tecnos.

Gil Gil, Alicia (2009): La justicia de transición en España: de la amnistía a la memoria histórica, Barcelona, Atelier.

Gil Gil, Alicia: "Sobre la satisfacción de la víctima como fin de la pena”, InDret, no 4, (2016)..

Gil Gil, Alicia: "El tratamiento jurídico de los crímenes cometidos en el conflicto armado colombiano. La problemática jurídica en el marco de la dicotomía paz-justicia”, en Gil Gil, Alicia; Maculan, Elena y Ferreira, Susana (dirs.) (2017): Colombia como nuevo modelo para la justicia de transición, Madrid, IUGM, pp. 22 y ss. 
Gil Gil, Alicia y Maculan, Elena (dirs.) (2017): La influencia de las víctimas en el tratamiento jurídico de la violencia colectiva, Madrid, Dykinson.

Gollwitzer, Mario y Denzler, Markus: "What makes revenge sweet: Seeing the offender suffer or delivering a message?", Journal of Experimental Social Psychology, no 45 (2009).

González Zapata, Julio: "La justicia transicional o la relegitimación del derecho penal", Estudios Políticos, n 31 (2007).

Grande, Elisabetta: "Dances of Criminal Justice: Thoughts on Systemic Differences and the Search for the Truth", en Jackson, John et al. (eds.) (2008): Crime, Procedure and Evidence in a Comparative and International Context, Oxford, Hart Publishing..

Gready, Paul y Robin, Simon: "From Transitional to Transformative Justice: A New Agenda for Practice" Internationakl Journal of Transitional Justice, $\mathrm{n}^{\circ} 8$ (2014).

Günther, Klaus (2002): "Die symbolisch-expressive Bedeutung der Strafe", en Festschrift für Klaus Lüderssen, Baden-Baden, Nomos..

Haque, Adil: "Group Violence and Group Vengeance: Toward a Retributivist Theory of International Criminal Law”, Buffalo Criminal Law Review, nº 9 (2005).

Harris, M. Kay: “An Expansive, Transformative View of Restorative Justice”, Contemporary Justice Review, no 7 (2004).

Hayner, Priscilla : "Fifteen Truth Commissions - 1974 to 1994: A Comparative Study", Human Rights Quarterly, nº 16 (1994).

Holz, Wilfried (2007): Justizgewähranspruch des Verbrechensopfers, Berlin, Duncker \& Humblot.

Hörnle, Tatjana: "Die Rolle des Opfers in der Straftheorie und im materiellen Strafrecht", Juristen Zeitung, no 19 (2006), pp. 955 y ss.

Huber, Florian (2007): La Ley de Justicia y Paz: desafíos y temas de debate, Bogotá, Friedrich Ebert Stiftung.

Jackson, Miles: “Amnesties in Strasbourg”, Oxford Journal of Legal Studies, vol. 38, n 3 (Autumn 2018).

Johnstone, Gerry y Van Ness, Daniel (eds.) (2007): Handbook of Restorative Justice, London, Willan.

Kant, Immanuel (1838): Die Metaphysik der Sitten, Modes und Baumann.

Kaufman, Armin (2013): Honor and Revenge. A Theory of Punishment, New York, Springer.

Lambourne, Wendy: “Transformative justice, reconciliation and peacebuilding”, en BuckleyZistel, Susanne et al. (eds.) (2014): Transitional Justice Theories, Routledge, pp. 19 y ss.

Leebaw, Bronwyn: “The Irreconciliable Goals of Transitional Justice", Human Rights Quarterly, nº 30 (2008), p. 118.

Liebmann, Marian (2007): Restorative Justice: How It Works, Jessica Kingsley.

Liñán Lafuente, Alfredo: "Los Tribunales penales híbridos e internacionalizados”, en Gil Gil, Alicia y Maculan, Elena (dirs.) (2019): Derecho penal internacional, Madrid, Dykinson, pp. 115 y ss.

Loddo, Olimpia G.: "Reciprocità di aspettative e aspettative di reciprocità nella vendetta", en Lorini, Giuseppe y Masia, Michelina (a cura di) (2015): Antropologia della vendetta, Napoli, ESI, p. 217. 
Lollini, Andrea (2011): Constitutionalism and transitional justice in South Africa, Oxford-New York, Berghan Books.

Luban, David: "Fairness to Rightness: Jurisdiction, Legality, and the Legitimacy of International Criminal Law", en Besson, Samantha y Tasioulas, John (eds) (2010): Philosophy of International Law, Oxford, OUP, pp. 577 y ss.

Lupária, Luca y Parizot, Raphaële: "Which good practices in the field of victim protection?", en Luca Luparia (ed.) (2015): Victims and criminal justice. European standards and national good practices, Wolters Kluwer.

Maculan, Elena: "El proceso transicional colombiano en perspectiva comparada", en Gil Gil, Alicia; Maculan, Elena y Ferreira, Susana (dirs.) (2017): Colombia como nuevo modelo para la justicia de transición, Madrid, IUGM, pp. 53 y ss.

Maculan, Elena: "Fines de la pena y del proceso penal en contextos de transición", en en Gil Gil, Alicia y Maculan, Elena (dirs.) (2017): La influencia de las víctimas en el tratamiento jurídico de la violencia colectiva, Madrid, Dykinson, pp. 207-240.

Maculan, Elena (2018): "Derecho penal, obligaciones internacionales y justicia de transición", Revista penal, $\mathrm{n}^{\circ} 41$ (2018), pp. 117 y ss.

Maculan, Elena: "La Corte Penal Internacional", en Gil Gil, Alicia y Maculan, Elena (dirs.) (2019): Derecho penal internacional, Madrid, Dykinson, pp. 83 y ss.

Malamud-Goti, Jaime (1990): "Transitional Government in the Breach: Why Punish State Criminals?", Human Rights Quarterly, vol. 1, n 12, pp. 1-16.

Malarino, Ezequiel: "Activismo judicial, punitivismo y nacionalización. Tendencias antidemocráticas y antiliberales de la Corte Interamericana de Derechos Humanos", en Ambos, Kai; Malarino, Ezequiel y Elsner, Gisela (coords.) (2010): Sistema interamericano de protección de los derechos humanos y derecho penal internacional, vol. I, Montevideo, KAS, pp. 25-61.

Malarino, Ezequiel : “Transición, derecho penal y amnistía. Reflexiones sobre la utilización del derecho penal en procesos de transición", Revista de Derecho Penal y Criminología, nº 9 (2013) p. 205-222.

Mallinder, Louise: "The End of Amnesty or Regional Overreach? Interpreting the Erosion of South America's Amnesty Laws", International and Comparative Law Quarterly, vol. 65, nº 3 (2016), pp. 645 y ss.

Miller, Dale T. (2001): "Disrespect and the Experience of Injustice", Annual Review of Psychology, $\mathrm{n}^{\circ} 52$ (2001).

Muñoz García, Juan Jesús y Navas Collado, Encarnación: "El daño psicológico en las víctimas del terrorismo", Revista de Psicopatología Clínica Legal y Forense, no 7 (2007), pp. 147 y ss.

Murph, Jeffrie y Hampton, Jean (1988): Forgiveness and Mercy, Cambridge, CUP, 1988.

Nino, Carlos S. (1996): Radical Evil on Trial, London, Yale University Press.

Osiel, Mark: "Why Prosecute? Critics of Punishment for Mass Atrocity", Human Rights Quarterly, n' 22, (2010).

Páez Rovira, Darío: “Afrontamiento y violencia colectiva”, en Idem et al. (coords.) (2011): Superando la violencia colectiva, construyendo cultura de paz, Fundamentos. 
Pastor, Daniel (2013): “Acerca de la verdad como derecho y como objeto exclusivo del proceso penal", en Maculan, Elena y Pastor, Daniel,(2013): El derecho a la verdad y su realización por medio del proceso penal, Buenos Aires, Hammurabi.

Pastor, Daniel R. (2006): El poder penal internacional, Barcelona, Atelier.

Pastor, Daniel R.: "La ideología penal de ciertos pronunciamientos de los órganos del sistema interamericano de derechos humanos: ¿garantías para el imputado, para la víctima o para el aparato represivo del Estado?", en Ambos, Kai; Malarino, Ezequiel y Elsner, Gisela (coords.) (2011): Sistema interamericano de protección de los derechos humanos y derecho penal internacional, vol. II, Montevideo, KAS, pp. 481 y ss.

Prittwitz, Cornelius: "The Resurrection of the Victim in Penal Theory", Buffalo Criminal Law, $n^{\circ} .3$ (1999).

Reemtsma, Jan Philipp (1999): Das Recht des Opfers auf die Bestrafung des Täters -als Problem, München, C.H. Beck.

Robinson, Paul H.: "The virtues of Restorative Processes, the Vices of "Restorative Justice", Utah Law Review, no 1 (2003).

Rodríguez Horcajo, Daniel (2016): Comportamiento humano, y pena estatal: disuasión, cooperación y equidad, Madrid, Marcial Pons.

Rodríguez Rodríguez, Jorge (2017): Derecho a la verdad y Derecho Internacional en relación con graves violaciones de los Derechos Humanos, Madrid, Instituto Berg.

Roth-Arriaza, Naomi (1995): Impunity and Human Rights in International Law and Practice, Oxford, OUP.

Sanz Díez de Ulzurrun, Marina: "Justicia restaurativa y mediación penal", en Gil Gil, Alicia y Maculan, Elena (dirs.) (2017): La influencia de las víctimas en el tratamiento jurídico de la violencia colectiva, Madrid, Dykinson.

Sarkin-Hughes, Jeremy (2004): Carrots and Sticks: The TRC and the South African Amnesty Process, Cambridge, Intersentia.

Schirch, Lisa: "Linking Human Rights and Conflict Transformation. A Peacebuilding Framework", en Mertus, Julie y Helsing, Jeffrey (eds.) (2006): Human Rights and Conflict. Exploring the Links between Rights, Law and Peacebuilding, New York, UN Institute for Peace Press.

Seibert-Fohr, Anja (2009): Prosecuting serious human rights violations, Oxford, OUP.

Seils, Paul: "Squaring Colombia's Circle. The Objectives of Punishment and the Pursuit of Peace”, ICTJ 2015, en https://www.ictj.org/publication/squaring-colombia-circle-objectivespunishment-peace.

Silva Sánchez, Jesús María: "Una crítica a las doctrinas penales de la "lucha contra la impunidad" y del "derecho de la víctima al castigo del autor"”, Revista de Estudios de la Justicia, no 11 (2009).

Silva Sánchez, Jesús María (2018): Malum passionis. Mitigar el dolor del Derecho penal, Barcelona, Atelier.

Stahn, Carsten: "The Geometry of Transitional Justice: Choices of Institutional Design", Leiden Journal of International Law, $\mathrm{n}^{\circ} 18$ (2005).

Sullivan, Dennis y Tifft, Larry: “The Transformative and Economic Dimensions of Restorative Justice”, Humanity \& Society, no 22 (1998), pp. 38-54. 